NBER WORKING PAPER SERIES

\title{
CAN'T WE ALL BE MORE LIKE SCANDINAVIANS? ASYMMETRIC GROWTH AND INSTITUTIONS IN AN INTERDEPENDENT WORLD
}

\author{
Daron Acemoglu \\ James A. Robinson \\ Thierry Verdier \\ Working Paper 18441 \\ http://www.nber.org/papers/w18441
NATIONAL BUREAU OF ECONOMIC RESEARCH
1050 Massachusetts Avenue
Cambridge, MA 02138
October 2012

We thank Pascual Restrepo for superb research assistance and Leopoldo Fergusson and seminar participants at Brown University, Copenhagen University, El Rosario University in Bogotá and 2011 Latin American and Caribbean Economic Association meetings for comments and suggestions. Acemoglu and Robinson gratefully acknowledge support from the Canadian Institute for Advanced Research. The views expressed herein are those of the authors and do not necessarily reflect the views of the National Bureau of Economic Research.

NBER working papers are circulated for discussion and comment purposes. They have not been peerreviewed or been subject to the review by the NBER Board of Directors that accompanies official NBER publications.

(C) 2012 by Daron Acemoglu, James A. Robinson, and Thierry Verdier. All rights reserved. Short sections of text, not to exceed two paragraphs, may be quoted without explicit permission provided that full credit, including $(\subset$ notice, is given to the source. 
Can't We All Be More Like Scandinavians? Asymmetric Growth and Institutions in an Interdependent World

Daron Acemoglu, James A. Robinson, and Thierry Verdier

NBER Working Paper No. 18441

October 2012

JEL No. O33,O40,P10,P16

\begin{abstract}
Because of their more limited inequality and more comprehensive social welfare systems, many perceive average welfare to be higher in Scandinavian societies than in the United States. Why then does the United States not adopt Scandinavian-style institutions? More generally, in an interdependent world, would we expect all countries to adopt the same institutions? To provide theoretical answers to this question, we develop a simple model of economic growth in a world in which all countries benefit and potentially contribute to advances in the world technology frontier. A greater gap of incomes between successful and unsuccessful entrepreneurs (thus greater inequality) increases entrepreneurial effort and hence a country's contribution to the world technology frontier. We show that, under plausible assumptions, the world equilibrium is asymmetric: some countries will opt for a type of "cutthroat capitalism" that generates greater inequality and more innovation and will become the technology leaders, while others will free- ride on the cutthroat incentives of the leaders and choose a more "cuddly" form of capitalism. Paradoxically, those with cuddly reward structures, though poorer, may have higher welfare than cutthroat capitalists; but in the world equilibrium, it is not a best response for the cutthroat capitalists to switch to a more cuddly form of capitalism. We also show that domestic constraints from social democratic parties or unions may be beneficial for a country because they prevent cutthroat capitalism domestically, instead inducing other countries to play this role.
\end{abstract}

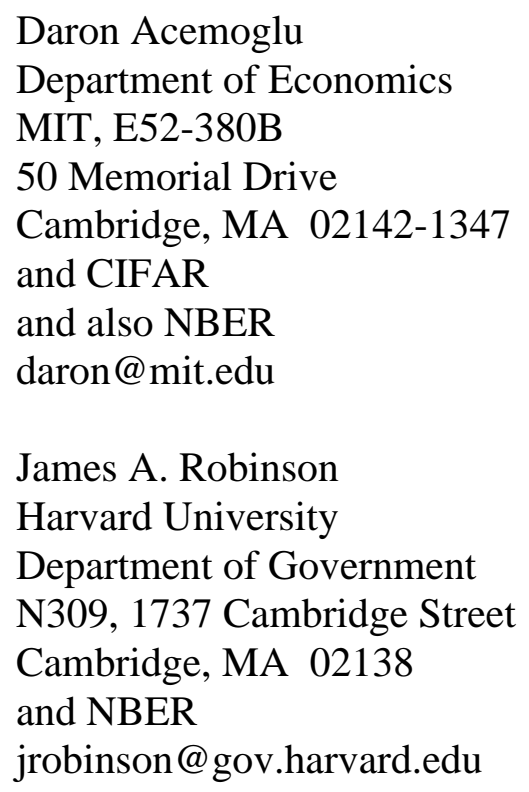

and CIFAR

and also NBER

James A. Robinson

Harvard University

Department of Government

N309, 1737 Cambridge Street

Cambridge, MA 02138

jrobinson@gov.harvard.edu

Thierry Verdier

PSE and ENPC

48 Boulevard Jourdan

75014 Paris France

and CEPR

verdier@pse.ens.fr 


\section{Introduction}

Against the background of the huge inequalities across countries, the United States, Denmark, Finland, Norway and Sweden are all prosperous, with per capita incomes more than 40 times those of the poorest countries around the world today. Over the last 60 years, all four countries have had similar growth rates. ${ }^{1}$ But there are also notable differences between them. The United States is richer than Denmark, Finland and Sweden, with an income per capita (in purchasing power parity, 2005 dollars) of about $\$ 43,000$ in 2008 . Denmark's is about $\$ 35,870$, Finland's is about $\$ 33,700$ and Sweden's stands at $\$ 34,300$ (OECD, 2011). ${ }^{2}$ The United States is also widely viewed as a more innovative economy, providing greater incentives to its entrepreneurs and workers alike, who tend to respond to these by working longer hours, taking more risks and playing the leading role in many of the transformative technologies of the last several decades ranging from software and hardware to pharmaceuticals and biomedical innovations. Figure 1 shows annual average hours of work in the United States, Denmark, Finland, Norway and Sweden since 1980, and shows the significant gap between the United States and the rest. ${ }^{3}$

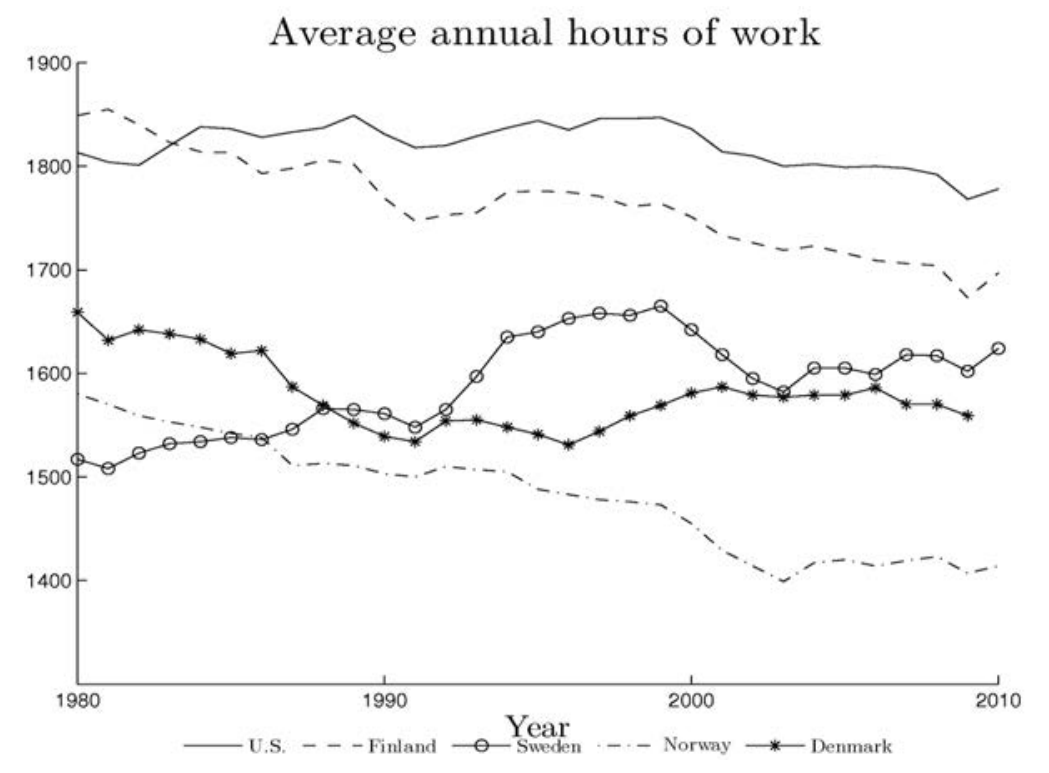

Figure 1: Annual average hours worked. Source: OECD (2010)

To illustrate the differences in innovation behavior, Figure 2 plots domestic patents per one million residents in these five countries since 1995, and shows an increasing gap between

\footnotetext{
${ }^{1}$ In particular, the average growth rates of income per capita in the United States, Denmark, Finland, Norway and Sweden between 1980 and 2009 are $1.59 \%, 1.50 \%, 1.94 \%, 2.33 \%$ and $1.56 \%$.

${ }^{2}$ Norway, on the other hand, has higher income per capita $(\$ 48,600)$ than the United States, but this comparison would be somewhat misleading since the higher Norwegian incomes are in large part due to oil revenues.

${ }^{3}$ Average annual hours are obtained by dividing total work hours by total employment. Data from the OECD Labor market statistics (OECD, 2010).
} 
the United States and the rest. ${ }^{4}$ These differences may partly reflect differential patenting propensities rather than differences in innovativeness, or may be driven by "less important" patents that contribute little to productive knowledge and will receive few cites (meaning that few others will build on them). To control for this difference, we adopt another strategy. ${ }^{5}$ We presume that important - highly-cited - innovations are more likely to be targeted to the world market and thus patented in the US patent office (USPTO). USPTO data enable us to use citation information. Figure 3 plots the numbers of patents granted per one million residents for Denmark, Finland, Norway and Sweden relative to the United States between 1980 and 1999. Each number corresponds to the relevant ratio once we restrict the sample to patents that obtain at least the number of citations (adjusted for year of grant) specified in the horizontal axis. ${ }^{6}$ If a country is more innovative (per resident) than the United States, we would expect the gap to close as we consider higher and higher thresholds for the number of citations. The figure shows that, on the contrary, the gap widens, confirming the pattern indicated by Figure 2 that the United States is more innovative (per resident) than these countries.

But there are also other important differences. The United States does not have the type of welfare state that many European countries, including Denmark, Finland, Norway and Sweden, have developed, and despite recent health-care reforms, many Americans do not enjoy the type of high-quality health care that their counterparts in these other countries do. They also receive much shorter vacations and more limited maternity leave, and do not have access to a variety of other public services that are more broadly provided in many continental European countries. Perhaps more importantly, poverty and inequality are much higher in the United States and have been increasing over the last three decades, while they have been broadly stable in Denmark, Finland, Norway and Sweden (see, e.g., Smeeding, 2002). Inequality at the top of the distribution has also been exploding in the United States, with the top $1 \%$ of earners capturing almost $25 \%$ of total national income, while the same number is around 5\% in Finland and Sweden (Atkinson, Piketty and Saez, 2011).

The economic and social performance of Denmark, Finland and Sweden, as well as several other European countries, raise the possibility that the US path to economic growth is not the

\footnotetext{
${ }^{4}$ These data are from the World Intellectual Property Organization Statistics Database (WIPO 2011). The WIPO construct these series by counting the total number of patent filings by residents in their own country patent office. For instance, 783 patent filings per million residents in 2010 in the US is obtained by dividing the total number of patent filings by US citizens at the US patent office (USPTO) by the number of residents in millions. Patents are likely to be filed at different offices, so adding numbers from different offices may count the same patent several times. Filings at own country office has the advantage that it avoids multiple filings; moreover, first time filings are more likely to occur at the inventor's home country office.

${ }^{5}$ Another plausible strategy would have been to look at patent grants in some "neutral" patent office or total number of world patterns. However, because US innovators appear less likely to patent abroad than Europeans, perhaps reflecting the fact that they have access to a larger domestic market, this seems to create an artificial advantage for European countries, and we do not report these results.

${ }^{6}$ Patents granted by the USPTO and citations are taken from the NBER US Patent Citations Data File. Citations are age-adjusted using the adjustment factor of Hall, Jaffe and Trajtenberg (2001), which is calculated by estimating an obsolescence-diffusion model in which citations are explained by technology field, grant year and citation lags. The model is then used to predict citations after the year 2006 since the data is truncated at this date. We do not include patents granted after 1999 so as not to excessively rely on this adjustment. For details on the methodology and data, see Hall, Jaffe and Trajtenberg (2001) or Kerr (2008).
} 


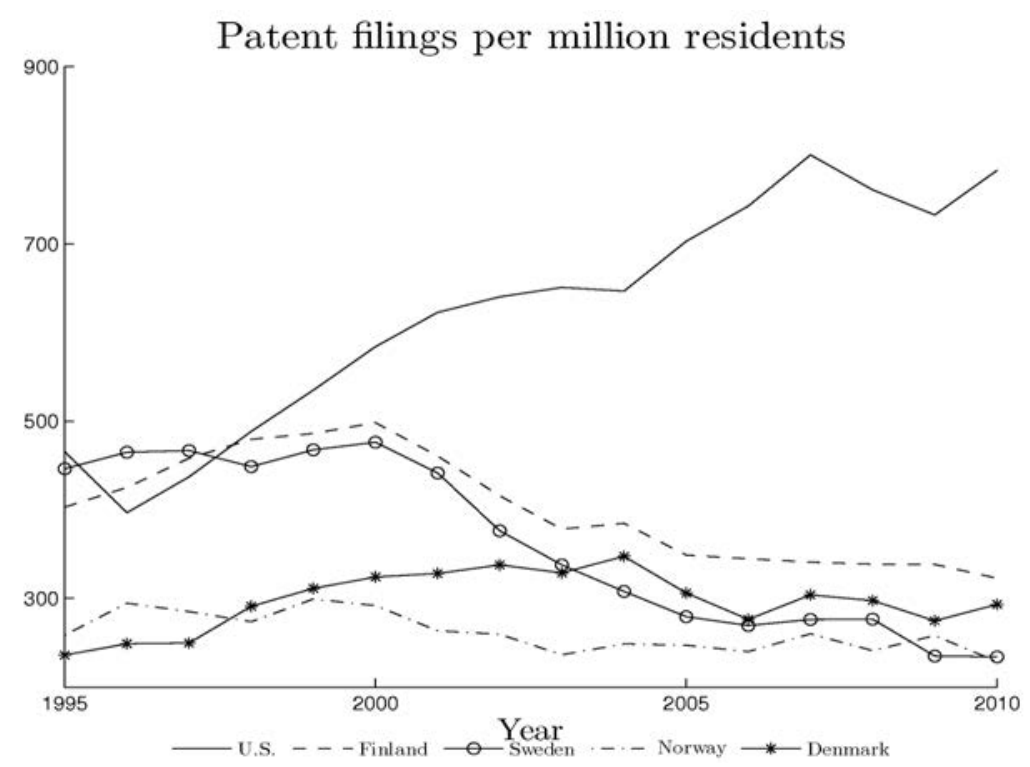

Figure 2: Patent filings per million residents at domestic office. Source: World Intellectual Property Organization.

only one, and nations can achieve prosperity within the context of much stronger safety net, more elaborate welfare states, and more egalitarian income distributions. Many may prefer to sacrifice 10 or $20 \%$ of GDP per capita to have better public services, a safety net, and a more equal society, not to mention to avoid the higher pressure that the US system may be creating. ${ }^{7}$ So can't we all-meaning all nations of the relatively developed world - be more like Scandinavians? Or can we?

The literature on "varieties of capitalism," pioneered by Hall and Soskice (2001), suggests that the answer is yes. They argue that a successful capitalist economy need not give up on social insurance to achieve rapid growth. They draw a distinction between a Coordinated Market Economy (CME) and a Liberal Market Economy (LME), and suggest that both have high incomes and similar growth rates, but CMEs have more social insurance and less inequality. Though different societies develop these different models for historical reasons and once set up institutional complementarities make it very difficult to switch from one model to another, Hall and Soskice suggest that an LME could turn itself into a CME with little loss in terms of income and growth - and with significant gains in terms of welfare.

In this paper, we suggest that in an interconnected world, the answer may be quite different. In particular, it may be precisely the more "cutthroat" American society that makes possible the more "cuddly" Scandinavian societies based on a comprehensive social safety net, the welfare state and more limited inequality. The basic idea we propose is simple and is developed in the context of a canonical model of endogenous technological change at the world level. The

\footnotetext{
${ }^{7}$ Schor (1993) was among the first to point out the comparatively much greater hours that American workers work. Blanchard (2004) has more recently argued that Americans may be working more than Europeans because they value leisure less.
} 


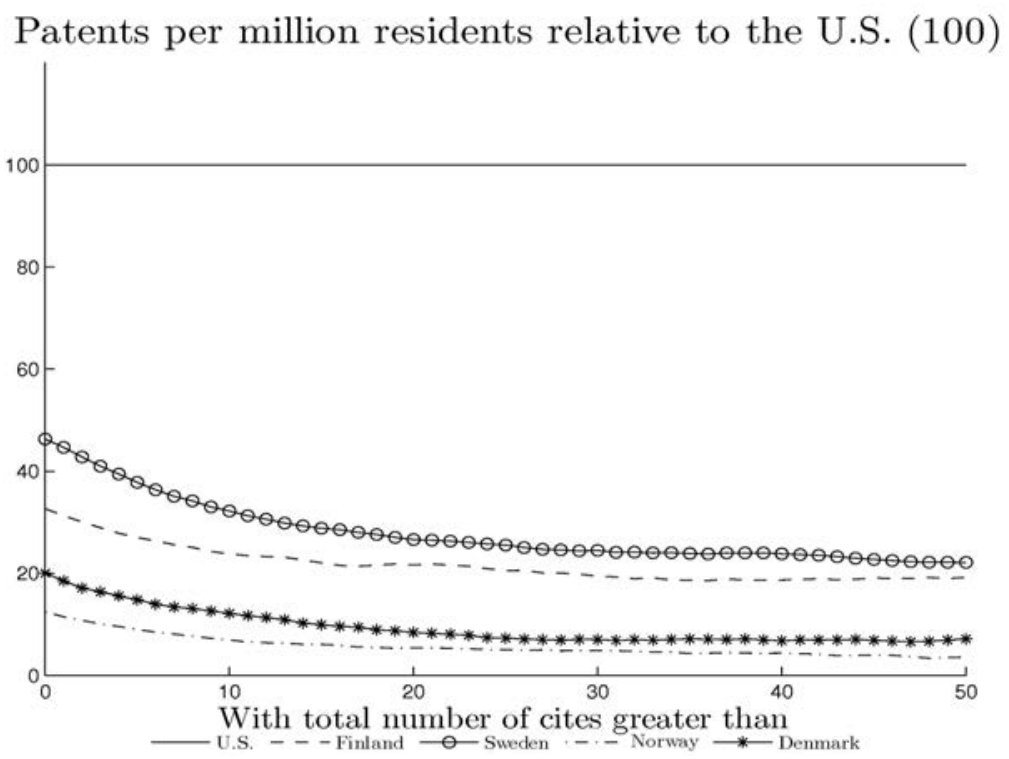

Figure 3: Patents granted between 1980-1999 per million residents to each country relative to the U.S. by number of citations. Source: NBER patent data from the USPTO.

main building block of our model is technological interdependence across countries: technological innovations, particularly by the most technologically advanced countries, contribute to the world technology frontier, and other countries can build on the world technology frontier. ${ }^{8}$ We combine this with the idea that technological innovations require incentives for workers and entrepreneurs. From the well-known incentive-insurance trade-off captured by the standard moral hazard models (e.g., Holmstrom, 1979), this implies greater inequality and greater poverty (and a weaker safety net) for a society encouraging innovation. Crucially, however, in a world with technological interdependences, when one (or a small subset) of societies is at the technological frontier and contributing disproportionately to its advancement, the incentives for others to do so will be weaker. In particular, innovation incentives by economies at the world technology frontier will create higher growth by advancing the frontier, while strong innovation incentives by followers will only increase their incomes today since the world technology frontier is already being advanced by the economies at the frontier. This logic implies that the world equilibriumwith endogenous technology transfer - may be asymmetric, and some countries will have greater incentives to innovate than others. Since innovation is associated with more high-powered incentives, these countries will have to sacrifice insurance and equality. The followers, on the other hand, can best respond to the technology leader's advancement of the world technology frontier by ensuring better insurance to their population - a better safety net, a welfare state and greater equality.

\footnotetext{
${ }^{8}$ Such knowledge spillovers are consistent with broad patterns in the data and are often incorporated into models of world equilibrium growth. See, Coe and Helpman (1995) and Keller (2001), Botazzi and Peri (2003), and Griffith, Redding and Van Reenen (2005) for some of the cross-industry evidence, and see, among others, Nelson and Phelps (1966), Howitt (2000), and Acemoglu, Aghion and Zilibotti (2006) for models incorporating international spillovers.
} 
The bulk of our paper formalizes these ideas using a simple (canonical) model of world equilibrium with technology transfer. Our model is a version of Romer's (1990) endogenous technological change model with multiple countries (as in Acemoglu, 2009, Chapter 18). R\&D investments within each economy advance that economy's technology, but these build on the knowledge stock of the world - the world technology frontier. Incorporating Gerschenkron (1962)'s famous insight, countries that are further behind the world technology frontier have an "advantage of backwardness" in that there is more unused knowledge at the frontier for them to build upon (see also Nelson and Phelps, 1966). We depart from this framework only in one dimension: by assuming, plausibly, that there is a moral hazard problem for workers (entrepreneurs) and for successful innovation they need to be given incentives, which comes at the cost of consumption insurance. ${ }^{9}$ A fully forward-looking (country-level) social planner chooses the extent of "safety net," which in our model corresponds to the level of consumption for unsuccessful economic outcomes for workers (or entrepreneurs). The safety net then determines a country-level reward structure shaping work and innovation incentives.

The main economic forces are simpler to see under two simplifying assumptions, which we adopt in our benchmark model. First, we focus on the case in which the world technology frontier is advanced only by the most advanced country's technology. Second, we assume that social planners (for each country) choose a time-invariant reward structure. Under these assumptions, and some simple parameter restrictions (which essentially require risk aversion and the gains from high effort to take intermediate values), we show that the world equilibrium is asymmetric: one country (the frontier economy) adopts a "cutthroat" reward structure, with high-powered incentives for success, while other countries free-ride on this frontier economy and choose a more egalitarian, "cuddly," reward structure. In the long-run, all countries grow at the same rate, but those with cuddly reward structures are strictly poorer. Notably, however, these countries may have higher welfare than the cutthroat leader. In fact, we prove that if the initial gap between the frontier economy and the followers is small enough, the cuddly followers will necessarily have higher welfare. Thus, our model confirms the intuition that all countries may want to be like the "Scandinavians" with a more extensive safety net and a more egalitarian structure. Yet the main implication of our theoretical analysis is that, under the assumptions of our model which we view as a fairly natural approximation to reality, we cannot all be like the Scandinavians. That is, it is not an equilibrium for the cutthroat leader, "the United States," to also adopt such a reward structure. This is because if, given the strategies of other countries, the cutthroat leader did so, this would reduce the growth rate of the entire world economy, discouraging the adoption of the more egalitarian reward structure. In contrast, followers are still happy to choose more egalitarian reward structures because this choice, though making them poorer, does not permanently reduce their growth rates, which are determined by the growth rate of the world technology frontier shaped by innovations in the cutthroat leader.

This result makes it clear that the egalitarian reward structures in the follower countries

\footnotetext{
${ }^{9}$ To do this in the most transparent fashion, we assume that the world consists of a sequence of one-period lived agents. We allow the social planner to have infinite horizon.
} 
are made possible by the positive externalities created by the cutthroat technology leader. So interpreting the empirical patterns in light of our theoretical framework, one may claim (with all the usual caveats of course) that the more harmonious and egalitarian Scandinavian societies are made possible because they are able to benefit from and free-ride on the knowledge externalities created by the cutthroat American equilibrium.

The rest of our paper shows that our simplifying assumptions are not crucial for these main insights, and also investigates the impact of other (domestic) institutional arrangements on the nature of the world equilibrium. First, we characterize the equilibrium of the dynamic game between (country-level) social planners that choose time-varying reward structures that are best responses to the current state of the world economy and the strategies of others (more formally, we look for the Markov perfect equilibrium of the game between the country social planners). In this case, the equilibrium generally is time varying, but the major insights are similar. An important difference is that in this case, we show that countries that start sufficiently far from the frontier will first adopt a cutthroat reward structure, and then switch to a cuddly, more egalitarian reward structure once they approach the frontier. The reason for this is instructive. The advantages of being backward, which are at the root of the long-run equilibrium leading to a stable world income distribution, also imply that the return to greater innovativeness is higher when a country is far from the world technology frontier. This encourages relatively backward countries to also adopt a cutthroat reward structure. Nevertheless, once an economy is sufficiently close to the world technology frontier, the same forces as in our time-invariant analysis kick in and encourage these follower economies to change their reward structures in a more egalitarian, cuddly direction. Thus, under some parameter restrictions, the time path of an economy has the flavor of the predictions of the "modernization theory," starting with a cutthroat reward structure and then changing in a more egalitarian direction to take advantage of better insurance for their citizens. Nevertheless, the intuition is very different from that of the approaches based on modernization theory, and the driving force is again the positive externalities created by the frontier economy. ${ }^{10}$

Second, we relax the assumption that the world technology frontier is affected only by innovation in the most technologically advanced country. We show that our main results extend to this case, provided that the function aggregating the innovation decisions of all countries into the world technology frontier is sufficiently convex. In particular, such convexity ensures that innovations by the more advanced countries are more important for world technological progress, and creates the economic forces towards an asymmetric equilibrium, which is at the root of our main result leading to an endogenous separation between cutthroat and cuddly countries.

Finally, we consider an extension in which we introduce domestic politics as a constraint on the behavior of the social planner. We do this in a simple, reduced-form, assuming that

\footnotetext{
${ }^{10}$ It is also worth nothing that the broad pattern implied by this analysis is in line with the fact that the more egalitarian reward structures and elements of the welfare state did not arise in follower countries integrated into the world economy in the postwar era such as South Korea and Taiwan until they became somewhat more prosperous.
} 
in some countries there is a strong labor movement (or social democratic party) ruling out reward structures that are very unequal. We show that if two countries start at the same level initially, the labor movement or social democratic party in country 1 may prevent cutthroat capitalism in that country, inducing a unique equilibrium in which country 2 is the one adopting the cutthroat reward structure. In this case, however, this is a significant advantage, because if the two countries start at the same level, the cutthroat country always has lower welfare. Therefore, a tradition of strong labor movement or social democratic party, by constraining the actions of the social planner, can act as a commitment device to egalitarianism, inducing an equilibrium in which the country in question becomes the beneficiary from the asymmetric world equilibrium. This result highlights that even if we cannot all be like Scandinavians, there are certain benefits from Scandinavian-type institutions - albeit at the cost of some other country in the world equilibrium adopting the cutthroat reward structure. This result thus also has the flavor of the domestic political conflicts in one country being "exported" to another, as the strength of the unions or the social democratic party in country 1 makes the poor in country 2 suffer more - as country 2 in response adopts a more cutthroat reward structure. ${ }^{11}$

It is also useful to discuss two further simplifying assumptions. First, we assume that interdependence across countries is purely technological. When countries trade, those with cutthroat incentives may specialize in different goods than those operating under cuddly reward structures. As shown in Acemoglu and Ventura (2001), in the presence of terms of trade effects the crosscountry growth and income level implications of models of growth and trade are similar to those with international technology spillovers (see also Acemoglu, 2009, Chapter 19), though in this context the feedback effects between institutional choices and specialization decisions introduce new and interesting economic forces. We leave an investigation of these issues to future research. Second, in practice Scandinavian countries may have chosen more redistributive policies than the US not only - not mainly - as a result of the trade-off between innovation incentives and social insurance, but also because of greater taste for redistribution or concerns of fairness among their voters. Naturally, this does not invalidate our analysis, and such differences can be readily incorporated into the preferences of the social planner without major changes in the formal analysis (but, of course, the resulting equilibrium is more likely to be asymmetric). More interestingly, our analysis in Section 5 shows that there will be a natural complementarity between this type of preference for redistribution and equilibrium reward structures in a global economy. For example, even a weak preference for redistribution might serve as a selection device, in the same way that a strong labor movement does in Section 5, ensuring that countries with greater preference for redistribution end up as institutional and technological followers, potentially with positive effects on their citizens' welfare.

Our paper is related to several different literatures. First, the issues we discuss are at the core of the "varieties of capitalism" literature in political science, e.g., Hall and Soskice (2001) which itself builds on earlier intellectual traditions offering taxonomies of different types of capitalism

\footnotetext{
${ }^{11}$ There is a parallel between this result and Davis (1998), even though Davis takes institutions as exogenous and emphasizes a very different mechanism.
} 
(Cusack, 2009) or welfare states (Esping-Anderson, 1990). A similar argument has also been developed by Rodrik (2008). As mentioned above, Hall and Soskice (2001) argue that while both CME and LMEs are innovative, they innovate in different ways and in different sectors. LMEs are good at "radical innovation" characteristic of particular sectors, like software development, biotechnology and semiconductors, while CMEs are good at "incremental innovation" in sectors such as machine tools, consumer durables and specialized transport equipment (see Taylor, 2004, and Akkermans, Castaldi, and Los, 2009, for assessments of the empirical evidence on these issues). This literature has not considered that growth in an CME might critically depends on innovation in the LMEs and on how the institutions of CMEs are influenced by this dependence. Most importantly, to the best of our knowledge, the point that the world equilibrium may be asymmetric, and different types of capitalism are chosen as best responses to each other, is new and does not feature in this literature. Moreover, we conduct our analysis within the context of a standard dynamic model of endogenous technological change and derive the world equilibrium from the interaction between multiple countries, which is different from the more qualitative approach of this literature.

Second, there is a related literature in economics, focusing on the causes of institutional differences across developed economies, and on why the US lacks a European style welfare state and why Europeans work less. Acemoglu and Pischke (1998) suggest an explanation for differences in labor market institutions between the US and Germany based on multiple equilibria in turnover, information and training investments. Landier (2005) develops a similar model to account for differences in entrepreneurial risk-taking between the US and France. Piketty (1995) proposes a model with multiple steady states, with potentially very different redistributive policies, driven by self-fulfilling beliefs about social mobility. Bénabou and Tirole (2006) develop a model in which self-fulfilling beliefs about justice and fairness can lead to divergent redistributive policies across countries. Bénabou's (2000) model is also related as it generates multiple equilibria, one with high inequality and low redistribution and another with low inequality and high redistribution, because redistribution can contribute to growth in the presence of capital market imperfections (see also Saint-Paul and Verdier, 1993, and Moene and Wallerstein, 1997). Another branch of the literature has emphasized the role of differences in fundamentals. These include: electoral systems with proportional representation, characteristic of continental, Europe may lead to greater redistribution (Alesina, Glaeser and Sacerdote, 2001, Milesi-Ferretti, Perotti and Rostagno, 2002, Persson and Tabellini, 2003, Alesina and Glaeser, 2004); or the federal nature of the US may lower redistribution (Cameron, 1978, Alesina, Glaeser and Sacerdote, 2001); or the greater ethnic heterogeneity of the US may reduce the demand for redistribution (Alesina, Glaeser and Sacerdote, 2001, Alesina and Glaeser, 2004); or greater social mobility in the US may mute the desire for redistributive taxation (Piketty, 1995, Bénabou and Ok, 2001, Alesina and La Ferrara, 2005), or redistribution may be greater in Northern Europe because of higher levels of social capital and trust (Algan, Cahuc and Sangnier, 2011). None of this work contains the core idea of this paper that the institutions of one country interact 
with those of another and that even with identical fundamentals asymmetric equilibria are the norm not an exception to explain.

Third, the idea that institutional differences may emerge endogenously depending on the distance to the world technology frontier has been emphasized in past work, for example, in Acemoglu, Aghion and Zilibotti (2006) (see also Krueger and Kumar, 2004). Nevertheless, this paper and others in this literature obtain this result from the domestic costs and benefits of different types of institutions (e.g., more or less competition in the product market), and the idea that activities leading to innovation are more important close to the world technology frontier is imposed as an assumption. In our model, this latter feature is endogenized in a world equilibrium, and the different institutions emerge as best responses to each other. Put differently, the distinguishing feature of our model is that the different institutions emerge as an asymmetric equilibrium of the world economy - while a symmetric equilibrium does not exist.

Finally, our results also have the flavor of "symmetry breaking" as in several papers with endogenous location of economic activity (e.g., Krugman and Venables, 1996, Matsuyama, 2002, 2005) or with endogenous credit market frictions (Matsuyama, 2007). These papers share with ours the result that similar or identical countries may end up with different choices and welfare levels in equilibrium, but the underlying mechanism and the focus are very different. ${ }^{12}$

The rest of the paper is organized as follows. Section 2 introduces the economic environment. Section 3 presents the main results of the paper under two simplifying assumptions; first, focusing on a specification where progress in the world technology frontier is determined only by innovation in the technologically most advanced economy, and second, supposing that countries have to choose time-invariant reward structures. Under these assumptions and some plausible parameter restrictions, we show that there does not exist a symmetric world equilibrium, and instead, one country plays the role of the technology leader and adopts a cutthroat reward structure, while the rest choose more egalitarian reward structures. Section 4 establishes that relaxing these assumptions does not affect our main results. Section 5 shows how domestic political economy constraints can be advantageous for a country because they prevent it from adopting a cutthroat reward structure. Section 6 concludes, and proofs omitted from the text are contained in the Appendix.

\section{Model}

In this section, we first describe the economic environment, which combines two components: the first is a standard model of endogenous technological change with knowledge spillovers across

\footnotetext{
${ }^{12}$ There is also a connection between our work and the literature on "dependency theory" in sociology, developed, among others, by Cardoso and Faletto (1979) and Wallerstein (1974-2011). (We thank Leopoldo Fergusson for pointing out this connection.) This theory argues that economic development in "core" economies, such as Western European and American ones, takes place at the expense of underdevelopment in the "periphery," and that these two patterns are self-reinforcing. In this theory, countries such as the United States that grow faster are the winners from this asymmetric equilibrium. In our theory, there is also an asymmetric outcome, though the mechanisms are very different, and indeed ours is more a model of "reverse dependency theory," since it is the Scandinavian "periphery" which, via free-riding, is benefiting from this asymmetric equilibrium.
} 
$J$ countries - and in fact closely follows Chapter 18 of Acemoglu (2009). The second introduces moral hazard on the part of entrepreneurs, thus linking entrepreneurial innovative activity of an economy to its reward structure. We then introduce "country social planners" who choose to reward structures within their country in order to maximize discounted welfare.

\subsection{Economic Environment}

Consider an infinite-horizon economy consisting of $J$ countries, indexed by $j=1,2, \ldots, J$. Each country is inhabited by non-overlapping generations of agents who live for a period of length $\Delta t$, work, produce, consume and then die. A continuum of agents, with measure normalized to 1 , is alive at any point in time in each country, and each generation is replaced by the next generation of the same size. We will consider the limit economy in which $\Delta t \rightarrow 0$, represented as a continuous time model.

The aggregate production function at time $t$ in country $j$ is

$$
Y_{j}(t)=\frac{1}{1-\beta}\left(\int_{0}^{N_{j}(t)} x_{j}(\nu, t)^{1-\beta} d \nu\right) L_{j}^{\beta},
$$

where $L_{j}$ is labor input, $N_{j}(t)$ denotes the number of machine varieties (or blueprints for machine varieties) available to country $j$ at time $t$. In our model, $N_{j}(t)$ will be the key state variable and will represent the "technological know-how" of country $j$ at time $t$. We assume that technology diffuses slowly and endogenously across countries as will be specified below. Finally, $x_{j}(\nu, t)$ is the total amount of machine variety $\nu$ used in country $j$ at time $t$. To simplify the analysis, we suppose that $x$ depreciates fully after use, so that the $x$ 's are not additional state variables. Crucially, blueprints for producing these machines, captured by $N_{j}(t)$, live on, and the increase in the range of these blueprints will be the source of economic growth.

Each machine variety in economy $j$ is owned by a technology monopolist, "entrepreneur," who sells machines embodying this technology at the profit-maximizing (rental) price $p_{j}^{x}(\nu, t)$ within the country (there is no international trade). This monopolist can produce each unit of the machine at a marginal cost of $\psi$ in terms of the final good, and without any loss of generality, we normalize $\psi \equiv 1-\beta$.

Suppose that each worker/entrepreneur exerts some effort $e_{j, i}(t) \in\{0,1\}$ to invent a new machine. Effort $e_{j, i}(t)=1$ costs $\gamma>0$ units of time, while $e_{j, i}(t)=0$ has no time cost. Thus, entrepreneurs who exert effort consume less leisure, which is costly. We also assume that entrepreneurial success is risky. When the entrepreneur exerts effort $e_{j, i}(t)=1$, he is "successful" with probability $q_{1}$ and unsuccessful with the complementary probability. If he exerts effort $e_{j, i}(t)=0$, he is successful with the lower probability $q_{0}<q_{1}$. Throughout we assume that effort choices are private information.

We assume the utility function of entrepreneur/worker $i$ takes the form

$$
U\left(C_{j, i}(t), e_{j, i}(t)\right)=\frac{\left[C_{j, i}(t)\left(1-\gamma e_{j, i}(t)\right)\right]^{1-\theta}-1}{1-\theta},
$$


where $\theta \geq 0$ is the coefficient of relative risk aversion (and the inverse of the intertemporal elasticity of substitution), and this form ensures balanced growth. ${ }^{13}$

We assume that workers can simultaneously work as entrepreneurs (so that there is no occupational choice). This implies that each individual receives wage income as well as income from entrepreneurship, and also implies that $L_{j}=1$ for $j=1, \ldots, J$.

An unsuccessful entrepreneur does not generate any new ideas (blueprints), while a successful entrepreneur in country $j$ generates

$$
\eta N(t)^{\phi} N_{j}(t)^{1-\phi}
$$

new ideas for machines, where $N(t)$ is an index of the world technology frontier, to be endogenized below, and $\eta>0$ and $\phi>0$ are assumed to be common across the $J$ countries. This form of the innovation possibilities frontier implies that the technological know-how of country $j$ advances as a result of the R\&D and other technology-related investments of entrepreneurs in the country, but the effectiveness of these efforts also depends on how advanced the world technology frontier is relative to this country's technological know-how. When it is more advanced, then the same sort of successful innovation will lead to more rapid advances, and the parameter $\phi$ measures the extent of this.

Given the likelihood of success by entrepreneurs as a function of their effort choices and defining $e_{j}(t)=\int e_{j, i}(t) d i$, technological advance in this country can be written as:

$$
\dot{N}_{j}(t)=\left(q_{1} e_{j}(t)+q_{0}\left(1-e_{j}(t)\right)\right) \eta N(t)^{\phi} N_{j}(t)^{1-\phi},
$$

We also assume that monopoly rights over the initial set of ideas are randomly allocated (independent of effort) to some of the current entrepreneurs, so that they are also produced monopolistically. ${ }^{14}$

Throughout, we maintain the following assumption: ${ }^{15}$

\section{Assumption 1:}

$$
\min \left\{q_{1}(1-\gamma)^{1-\theta}-q_{0},\left(1-q_{0}\right)-\left(1-q_{1}\right)(1-\gamma)^{1-\theta}\right\}>0
$$

Finally, the world technology frontier is assumed to be given by

$$
N(t)=G\left(N_{1}(t), \ldots, N_{J}(t)\right),
$$

\footnotetext{
${ }^{13}$ When $\theta=1$, the utility function in $(2)$ converges to $\ln C_{j, i}(t)+\ln \left(1-\gamma e_{j, i}(t)\right)$. All of our results apply to this case also, but in what follows we often do not treat this case separately to save space.

${ }^{14}$ The alternative is to assume that existing machines are produced competitively. This has no impact on any of the results in the paper, and would just change the value of $B$ in (10) below.

${ }^{15}$ This assumption ensures that, both when $\theta<1$ and when $\theta>1$, effort will only be forthcoming if entrepreneurs are given incentives. That is, it is sufficient to guarantee that with the same consumption conditional on success and failure, no entrepreneur would choose to exert effort. Why Assumption 1 ensures this can be seen from equation (9).
} 
where $G$ is a linearly homogeneous function. We will examine two special cases of this function. The first is

$$
G\left(N_{1}(t), \ldots, N_{J}(t)\right)=\max \left\{N_{1}(t), \ldots, N_{J}(t)\right\} .
$$

which implies that the world technology frontier is given by the technology level of the most advanced country, the technology leader, and all other countries benefit from the advances of this technological leader. The second is a more general convex aggregator

$$
G\left(N_{1}(t), \ldots, N_{J}(t)\right)=\frac{1}{J}\left[\sum_{j=1}^{J} N_{j}(t)^{\frac{\sigma-1}{\sigma}}\right]^{\frac{\sigma}{\sigma-1}},
$$

with $\sigma<0$. As $\sigma \uparrow 0$ (6) converges to (5). For much of the analysis, we focus on the simpler specification (5), though at the end of Section 4 we show that our general results are robust when we use (6) with $\sigma$ sufficiently small.

\section{$2.2 \quad$ Reward Structures}

As noted above, entrepreneurial effort levels will depend on the reward structure in each country, which determines the relative rewards to successful entrepreneurship. In particular, suppressing the reference to country $j$ to simplify notation, let $\tilde{R}_{s}(t)$ denote the time $t$ entrepreneurial income for successful entrepreneurs and $\tilde{R}_{u}(t)$ for unsuccessful entrepreneurs. Thus the total income of a worker/entrepreneur is

$$
R_{i}(t)=\tilde{R}_{i}(t)+w(t)
$$

where $w(t)$ is the equilibrium wage at time $t .{ }^{16}$ In what follows, it is sufficient to look at the total income $R_{i}$ rather than just the entrepreneurial component $\tilde{R}_{i}$. The reward structure can then be summarized by the ratio $r(t) \equiv R_{s}(t) / R_{u}(t)$. When $r(t)=1$, there is perfect consumption insurance at time $t$, but this generates effort $e=0$. Instead, to encourage $e=1$, the summary index of the reward structure $r(t)$ needs to be above a certain threshold, which we characterize in the next section.

This description makes it clear that countries will have a choice between two styles of capitalism: "cutthroat capitalism" in which $r(t)$ is chosen above a certain threshold, so that entrepreneurial success is rewarded while failure is at least partly punished, and "cuddly capitalism" in which $r(t)=1$, so that there is perfect equality and consumption insurance, but this comes at the expense of lower entrepreneurial effort and innovation.

Throughout we assume that the sequence of reward structures in country $j,\left[r_{j}(t)\right]_{t=0}^{\infty}$ is chosen by its country-level social planner. This assumption enables us to construct a simple game between countries (in particular, it enables us to abstract from within-country political

\footnotetext{
${ }^{16}$ Thus both $\tilde{R}_{u}(t)$ and $\tilde{R}_{s}(t)$ include the rents that entrepreneurs make in expectation because of existing ideas being randomly allocated to them.
} 
economy issues until later). Limiting the social planner to only choose the sequence of reward structures is for simplicity and without any consequence. ${ }^{17}$

The most natural objective function for the social planner is the discounted welfare of the citizens in that country, given by

$$
\int_{0}^{\infty} e^{-\rho t}\left(\int U\left(C_{j, i}(t), e_{j, i}(t)\right) d i\right) d t=\int_{0}^{\infty} e^{-\rho t}\left(\int \frac{\left[C_{j, i}(t)\left(1-\gamma e_{j, i}(t)\right)\right]^{1-\theta}-1}{1-\theta} d i\right) d t
$$

where $\rho$ is the discount rate that the social planner applies to future generations and $U\left(C_{j, i}(t), e_{j, i}(t)\right)$ denotes the utility of agent $i$ in country $j$ alive at time $t$ (and thus the inner integral averages across all individuals of that generation). One disadvantage of this objective function is that it imposes that the inverse of the intertemporal elasticity of substitution is equal to the coefficient of relative risk aversion. Since comparative statics with respect to the coefficient of relative risk aversion are of interest, this feature is not desirable. For this reason, we will also discuss the results with Epstein-Zin preferences for social planners (Epstein and Zin, 1989), which separate the coefficient of relative risk aversion from the intertemporal elasticity of substitution. These preferences, in continuous time, take the form:

$$
\left[\int_{0}^{\infty} e^{-\rho t}\left[\int\left(\frac{\left[C_{j, i}(t)\left(1-\gamma e_{j, i}(t)\right)\right]^{1-\theta}}{1-\theta}\right) d i\right]^{\frac{1-\lambda}{1-\theta}} d t\right]^{\frac{1}{1-\lambda}}
$$

where $\theta$ is still the coefficient of relative risk aversion, but now the inverse of the intertemporal elasticity of substitution is given by $\lambda$. When $\lambda=\theta$, we got back to (7).

\section{Equilibrium with Time-Invariant Reward Structures}

In this section, we simplify the analysis by assuming that the reward structure for each country $j$ is time-invariant, i.e., $r_{j}(t)=r_{j}$, and is chosen at time $t=0$. This assumption implies that each country chooses between "cuddly" and "cutthroat" capitalism once and for all, and enables us to characterize the structure of the world equilibrium in a transparent manner, showing how this equilibrium often involves different choices of reward structures across countries - in particular, one country choosing cutthroat capitalism while the rest choose cuddly capitalism. In this section, we focus on the "max" specification of the world technology frontier given by (5), and we also start with the simpler objective for the social planner given by the discounted utilities of different generations as in (7).

\subsection{World Equilibrium Given Reward Structures}

We first characterize the dynamics of growth for given (time-invariant) reward structures. The following proposition shows that a well-defined world equilibrium exists and involves all countries growing at the same rate, set by the rate of growth of the world technology frontier. This

\footnotetext{
${ }^{17}$ If we allow the social planner to set prices that prevent the monopoly markup, nothing in our analysis below, except that the value of $B$ in (10), would change.
} 
growth rate is determined by the innovation rates (and thus reward structures) of either all countries (with (6)) or the leading country (with (5)). In addition, differences in reward structures determine the relative income of each country.

Proposition 1 Suppose that the reward structure for each country is constant over time (i.e., for each $\left.j, R_{s}^{j}(t) / R_{u}^{j}(t)=r_{j}\right)$. Then starting from any initial condition $\left(N_{1}(0), \ldots, N_{J}(0)\right)$, the world economy converges to a unique stationary distribution $\left(n_{1}^{*}, \ldots, n_{J}^{*}\right)$, where $n_{j}(t) \equiv$ $N_{j}(t) / N(t)$ and $\dot{N}(t) / N(t)=g^{*}$, and $\left(n_{1}^{*}, \ldots, n_{J}^{*}\right)$ and $g^{*}$ are functions of $\left(r_{1}, \ldots, r_{J}\right)$. Moreover, with the max specification of the world technology frontier, (5), $g^{*}$ is only a function of the most innovative country's reward structure, $r_{\ell}$.

Proof. The proof of this proposition follows from the material in Chapter 18 of Acemoglu (2009) with minor modifications and is omitted to save space.

The process of technology diffusion ensures that all countries grow at the same rate, even though they may choose different reward structures. In particular, countries that do not encourage innovation will first fall behind, but given the form of technology diffusion in equation (3), the advances in the world technology frontier will also pull them to the same growth rate as those that provide greater inducements to innovation. The proposition also shows that in the special case where (5) applies, it will be only innovation and the reward structure in the technologically most advanced country that determines the world growth rate, $g^{*}$.

\subsection{Cutthroat and Cuddly Reward Structures}

We now define the cutthroat and cuddly reward structures. Consider the reward structures that ensure effort $e=1$ at time $t$. This will require that the incentive compatibility constraint for entrepreneurs be satisfied at $t$, or in other words, expected utility from exerting effort $e=1$ should be greater than expected utility from $e=0$. Using (2), this requires

$$
\frac{1}{1-\theta}\left(q_{1} R_{s}(t)^{1-\theta}+\left(1-q_{1}\right) R_{u}(t)^{1-\theta}\right)(1-\gamma)^{1-\theta} \geq \frac{1}{1-\theta}\left(q_{0} R_{s}(t)^{1-\theta}+\left(1-q_{0}\right) R_{u}(t)^{1-\theta}\right)
$$

where recall that $R_{s}(t)$ is the income and thus the consumption of an entrepreneur/worker conditional on successful innovation, and $R_{u}(t)$ is the income level when unsuccessful, and this expression takes into account that high effort leads to success with probability $q_{1}$ and low effort with probability $q_{0}$, but with high effort the total amount of leisure is only $1-\gamma$. Rearranging this expression, we obtain

$$
\begin{aligned}
r(t) \equiv \frac{R_{s}(t)}{R_{u}(t)} & \geq\left(\frac{\left(1-q_{0}\right)-\left(1-q_{1}\right)(1-\gamma)^{1-\theta}}{q_{1}(1-\gamma)^{1-\theta}-q_{0}}\right)^{\frac{1}{1-\theta}} \\
& =\left(1+\frac{1-(1-\gamma)^{1-\theta}}{q_{1}(1-\gamma)^{1-\theta}-q_{0}}\right)^{\frac{1}{1-\theta}} \equiv A .
\end{aligned}
$$

Clearly, the expression $A$ defined in (9) measures how "high-powered" the reward structure needs to be in order to induce effort, and will thus play an important role in what follows. Assumption 
1 is sufficient to ensure that $A>1 .^{18}$

Since the social planner maximizes average utility, she would like to achieve as much consumption insurance as possible subject to the incentive compatibility constraint (9), which implies that she will satisfy this constraint as equality. In addition, $R_{s}(t)$ and $R_{u}(t)$ must satisfy the resource constraint at time $t$. Using the expression for total output and expenditure on machines provided in the Appendix, this implies

$$
q_{1} R_{s}(t)+\left(1-q_{1}\right) R_{u}(t)=B N_{j}(t)
$$

where

$$
B \equiv \frac{\beta(2-\beta)}{1-\beta},
$$

and we are using the fact that in this case, all entrepreneurs will exert high effort, so a fraction $q_{1}$ of them will be successful. Combining this expression with (9), we obtain

$$
R_{s}(t)=\frac{B A}{q_{1} A+\left(1-q_{1}\right)} N_{j}(t) \text { and } R_{u}(t)=\frac{B}{q_{1} A+\left(1-q_{1}\right)} N_{j}(t) .
$$

The alternative to a reward structure that encourages effort is one that forgoes effort and provides full consumption insurance -i.e., the same level of income to all entrepreneur/workers of $R_{0}(t)$, regardless of whether they are successful or not. In this case, the same resource constraint implies

$$
R_{0}(t)=B N_{j}(t)
$$

Given these expressions, the expected utility of entrepreneurs/workers under the "cutthroat" and "cuddly" capitalist systems, denoted respectively by $s=c$ and $s=o$, can be rewritten as

$$
\begin{aligned}
W_{j}^{c}(t) & \equiv \mathbb{E}\left[U\left(C_{j}^{c}(t), e_{j}^{c}(t)\right)\right]=\frac{\left(q_{1} R_{s}(t)^{1-\theta}+\left(1-q_{1}\right) R_{u}(t)^{1-\theta}\right)(1-\gamma)^{1-\theta}-1}{1-\theta}, \\
W_{j}^{o}(t) & \equiv \mathbb{E}\left[U\left(C_{j}^{o}(t), e_{j}^{o}(t)\right)\right]=\frac{R_{0}(t)^{1-\theta}-1}{1-\theta} .
\end{aligned}
$$

Now using (11) and (12), we can express these expected utilities as: ${ }^{19}$

$$
W_{j}^{c}(t)=\omega_{c} N_{j}(t)^{1-\theta}-\frac{1}{1-\theta} \text { and } W_{j}^{o}(t)=\omega_{o} N_{j}(t)^{1-\theta}-\frac{1}{1-\theta},
$$

where

$$
\omega_{c} \equiv \frac{\left(q_{1} A^{1-\theta}+\left(1-q_{1}\right)\right)(1-\gamma)^{1-\theta}}{\left(q_{1} A+\left(1-q_{1}\right)\right)^{1-\theta}} \frac{B^{1-\theta}}{1-\theta} \text { and } \omega_{o} \equiv \frac{B^{1-\theta}}{1-\theta} .
$$

It can be verified that $\omega_{c}<\omega_{o}$, though when $\theta>1$, it important to observe that we have $\omega_{c}<\omega_{o}<0$. It can also be established straightforwardly that $\omega_{c}$, and thus $\left(\omega_{c} / \omega_{o}\right)^{1 /(1-\theta)}$, is decreasing in $A$, defined in (9), (since a higher $A$ translates into greater consumption variability);

\footnotetext{
${ }^{18}$ In particular, when $\theta<1,1+\frac{1-(1-\gamma)^{1-}-\theta}{q_{1}(1-\gamma)^{1-\theta}-q_{0}}$ is greater than one and is raised to a positive power, while when $\theta>1$, it is less than one and it is raised to a negative power.

${ }^{19}$ In what follows, we will also drop the constant $-1 /(1-\theta)$ in $W_{j}^{c}(t)$ and $W_{j}^{o}(t)$ when this causes no confusion.
} 
that $A$ (and thus $\left(\omega_{c} / \omega_{o}\right)^{1 /(1-\theta)}$ ) is increasing in $\gamma$ (to compensate for the higher cost of effort); and that $A$ is non-monotone in $\theta$ (because a higher coefficient of relative risk aversion also reduces the disutility of effort).

From (3), the growth rate of technology of country $j$ adopting reward structure $s_{j} \in\{c, o\}$ can be derived as

$$
\dot{N}_{j}(t)=g_{s_{j}} N(t)^{\phi} N_{j}(t)^{1-\phi}
$$

where the growth rates $g_{s_{j}} \in\left\{g_{c}, g_{o}\right\}$ are given by

$$
g_{o} \equiv q_{0} \eta \text {, and } g_{c} \equiv q_{1} \eta \text {. }
$$

This reiterates that at any point in time, a country choosing a cutthroat reward structure will have a faster growth of its technology stock.

We next introduce a second assumption, which ensures that the cutthroat growth rate, $g_{c}$, is not so high as to lead to infinite welfare for the country social planners and will also be maintained throughout (without explicitly being stated):

\section{Assumption 2:}

$$
\rho-(1-\theta) g_{c}>0
$$

\subsection{Equilibrium Reward Structures}

We now characterize the equilibrium of the game between the country social planners. Since reward structures are chosen once and for all at time $t=0$, the interactions between the country social planners can be represented as a static game with the payoffs given as the discounted payoffs implied by the reward structures of all countries (given initial conditions $\left\{N_{1}(0), \ldots, N_{J}(0)\right\}$ ). We will characterize the Nash equilibria of this static game. We also restrict attention to the situation in which the same country, denoted $\ell$, remains the technology leader throughout. Given our focus on the world technology frontier specification in (5), the fact that this country is the leader implies at each $t$ implies that $N_{\ell}(t)=\max \left\{N_{1}(t), \ldots, N_{J}(t)\right\}$ for all $t$. This assumption simplifies the exposition in this section. ${ }^{20}$

We next introduce the key condition which will ensure that the technology leader prefers a cutthroat reward structure. It is straightforward to verify that when this condition is not satisfied, all countries will choose a cuddly reward structure. Thus this condition restricts attention to the interesting part of the parameter space.

\section{Condition 1:}

$$
\frac{\omega_{c}}{\rho-(1-\theta) g_{c}}>\frac{\omega_{o}}{\rho-(1-\theta) g_{o}}
$$

\footnotetext{
${ }^{20}$ Essentially, it enables us to pick a unique equilibrium among asymmetric equilibria. A byproduct of the analysis in Section 5 is to show how this assumption can be relaxed without affecting our main results.
} 
Why this condition ensures that the technology leader, country $\ell$, prefers a cutthroat reward structure can be seen straightforwardly by noting that when the growth rate of the world technology frontier is determined by innovation in country $\ell, \frac{\omega_{c}}{\rho-(1-\theta) g_{c}}$ is the discounted value from such a cutthroat reward structure, while the discounted value of a cuddly reward structure is $\frac{\omega_{o}}{\rho-(1-\theta) g_{o}}$ given that all other countries are choosing a cuddly strategy. ${ }^{21}$

Now recalling that $n_{j}(t) \equiv N_{j}(t) / N(t)=N_{j}(t) / N_{\ell}(t)$, for $j \neq \ell$ we have

$$
\frac{\dot{n}_{j}(t)}{n_{j}(t)}=\left(\frac{N_{\ell}(t)}{N_{j}(t)}\right)^{\phi} g_{s_{j}}-g_{\ell}=n_{j}(t)^{-\phi} g_{s_{j}}-g_{\ell} .
$$

where $g_{\ell}=g_{c}$, and we have imposed that the leader is choosing a cutthroat reward structure. This differential equation's solution is

$$
N_{j}(t)=\left(N_{j}(0)^{\phi}+\frac{g_{s_{j}}}{g_{c}}\left(e^{\phi g_{c} t}-1\right)\left(N_{\ell}(0)\right)^{\phi}\right)^{\frac{1}{\phi}},
$$

enabling us to evaluate the welfare of the country $j$ social planner from reward structure $s_{j} \in$ $\{c, o\}:$

$$
\begin{aligned}
\mathcal{W}_{j}\left(s_{j}\right) & =\int_{0}^{\infty} e^{-\rho t} W_{j}^{s_{j}}(t)=\int_{0}^{\infty} e^{-\rho t} \omega_{s_{j}} N_{\ell}(0)^{1-\theta}\left(n_{j}(0)^{\phi}+\frac{g_{s_{j}}}{g_{c}}\left(e^{\phi g_{c} t}-1\right)\right)^{\frac{1-\theta}{\phi}} d t \\
& =\omega_{s_{j}} N_{\ell}(0)^{1-\theta}\left(\frac{g_{s_{j}}}{g_{c}}\right)^{\frac{1-\theta}{\phi}} \int_{0}^{\infty} e^{-\left(\rho-(1-\theta) g_{c}\right) t}\left(1+\left(\frac{g_{c}}{g_{s_{j}}} n_{j}(0)^{\phi}-1\right) e^{-\phi g_{c} t}\right)^{\frac{1-\theta}{\phi}} d t
\end{aligned}
$$

where recall that $n_{j}(0) \equiv N_{j}(0) / N_{\ell}(0)$. The second line of (15) highlights that, under Condition 1 , the long-run growth rate of all countries will be $g_{c}$, and thus ensure that these welfare levels are well defined. This implies the following straightforward result:

Proposition 2 Suppose that each country chooses a time-invariant reward structure at time $t=0$. Suppose also that country social planners maximize (7), the world technology frontier is given by (5), Condition 1 holds, and

$$
\left(\frac{\omega_{c}}{\omega_{o}}\right)^{\frac{1}{1-\theta}}<\left(\frac{g_{o}}{g_{c}}\right)^{\frac{1}{\phi}}\left(\frac{\int_{0}^{\infty} e^{-\left(\rho-(1-\theta) g_{c}\right) t}\left(1+\left(\frac{g_{c}}{g_{o}} n_{j}(0)^{\phi}-1\right) e^{-\phi g_{c} t}\right)^{\frac{1-\theta}{\phi}} d t}{\int_{0}^{\infty} e^{-\left(\rho-(1-\theta) g_{c}\right) t}\left(1+\left(n_{j}(0)^{\phi}-1\right) e^{-\phi g_{c} t}\right)^{\frac{1-\theta}{\phi}} d t}\right)^{\frac{1}{1-\theta}} \text { for each } j \neq \ell .
$$

Then there exists no symmetric equilibrium. Moreover, there exists a unique world equilibrium in which the initial technology leader, country $\ell$ remains so throughout, and this equilibrium involves country $\ell$ choosing a cutthroat reward structure, while all other countries choose a cuddly reward structure. In this world equilibrium, country $\ell$ grows at the rate $g_{c}$ throughout, while all other countries asymptotically grow also at this rate, and converge to a level of income equal to a fraction $g_{o} / g_{c}$ of the level of income of country $\ell$.

\footnotetext{
${ }^{21}$ If the country in question chose a cuddly reward structure while some other country chose the cutthroat structure, then this other country would necessarily become the leader at some point. Here we are restricting attention to the case in which this other country would be the leader from the beginning, which is without much loss of generality.
} 
Proof. Suppose first that country $\ell$ chooses a cutthroat reward structures throughout. Then the result that country $j$ strictly prefers to choose a cuddly reward structure follows immediately from comparing $\mathcal{W}_{j}(c)$ and $\mathcal{W}_{j}(o)$ given by (15) (remembering that when $\theta>1$, we have $\omega_{c}<$ $\omega_{o}<0$ and thus the direction of inequality is reversed twice, first when we divide by $\omega_{o}$ and second when we raise the left-hand side to the power $1 /(1-\theta))$.

The result that there exists no symmetric equilibrium in which all countries choose the same reward structure follows from this observation: when (16) holds, all $j \neq \ell$ will choose a cuddly reward structure when $\ell$ chooses a cutthroat one; and Condition 1 implies that when $j \neq \ell$ choose a cuddly reward structure, country $\ell$ strictly prefers to choose a cutthroat one. This also characterizes the unique equilibrium in which $\ell$ remains the technology leader throughout.

Finally, convergence to a unique stationary distribution of income with the same asymptotic growth rate follows from Proposition 1, and the ratio of income between the leader and followers in this stationary distribution is given from the limit of equation (14).

The important implication is that, under the hypotheses of the proposition, the world equilibrium is necessarily asymmetric - i.e., a symmetric equilibrium does not exist. Rather, it involves one country choosing a cutthroat reward structure, while all others choose cuddly reward structures. The intuition for this result comes from the differential impacts of the leader, country $\ell$, and non-leader countries on the world growth rate. Because country $\ell$ 's innovations and reward structure determine the pace of change of the world technology frontier, if it were to switch from a cutthroat to a cuddly reward structure, this would have a growth effect on the world economy (and thus on itself). The prospect of permanently lower growth discourages country $\ell$ from choosing a cuddly reward structure. In contrast, any other country deviating from the asymmetric equilibrium and choosing a cutthroat reward structure would only enjoy a beneficial level effect: such a country would increase its position relative to country $\ell$, but would not change its long-run growth rate (because its growth rate is already high thanks to the spillovers from the cutthroat incentives that country $\ell$ provides to its entrepreneurs). The contrast between the growth effect of the reward structure of the leader and the level effect of the reward structure of followers is at the root of the asymmetric equilibrium (and the non-existence of asymmetric equilibrium). ${ }^{22}$

Condition (16), which ensures that the world equilibrium is asymmetric, is in terms of the ratio of two integrals which do not in general have closed-form solutions. Nevertheless, the special case where $\phi=1-\theta$ admits a closed-form solution and is useful to illustrate the main

\footnotetext{
${ }^{22}$ Naturally, with any asymmetric equilibrium of this type, there are in principle several equilibria, with one country playing the role of the leader and choosing a cutthroat reward structure, while others choose cuddly reward structures. Uniqueness here results from the fact that we have imposed that the same country remains the leader throughout, which picks the initial technology leader as the country choosing the cutthroat reward structure.
} 
insights. In particular, in this case (16) simplifies to :

$$
\left(\frac{\omega_{c}}{\omega_{o}}\right)<\left(\frac{g_{o}}{g_{c}}\right)\left(\frac{\int_{0}^{\infty} e^{-\left(\rho-\phi g_{c}\right) t}\left(1+\left(\frac{g_{c}}{g_{o}} n_{j}(0)^{\phi}-1\right) e^{-\phi g_{c} t}\right) d t}{\int_{0}^{\infty} e^{-\left(\rho-\phi g_{c}\right) t}\left(1+\left(n_{j}(0)^{\phi}-1\right) e^{-\phi g_{c} t}\right) d t}\right)=\frac{n_{j}(0)^{\phi}\left(\rho-\phi g_{c}\right)+\phi g_{o}}{n_{j}(0)^{\phi}\left(\rho-\phi g_{c}\right)+\phi g_{c}}
$$

Inspection of (17) shows that an asymmetric equilibrium is more likely to emerge when $n_{j}(0)$ is close to 1 for all followers - since the last expression is strictly increasing in $n_{j}(0)$. This implies that, bearing in mind that country $\ell$ is the technology leader initially, the asymmetric equilibrium is more likely to emerge when all countries are relatively equal to start with. Intuitively, the innovation possibilities frontier (3) implies that a country that is further behind the world technology frontier (i.e., low $\left.n_{j}(0)\right)$ has a greater growth potential - and in fact will grow faster for a given level of innovative activity. This also implies that the additional gain in growth from choosing a cutthroat reward structure is greater the lower is $n_{j}(0)$. Consequently, for countries that are significantly behind the world technology frontier (or behind country $\ell$ ), the incentives to also adopt a cutthroat reward structure are stronger. ${ }^{23}$ The next figure illustrates this diagrammatically. The upward sloping curve plots the right-hand side of (17) as a function of $n_{j}(0)$. When this expression is equal to $\omega_{c} / \omega_{o}$, country $j$ is indifferent between a cuddly and cutthroat reward structure, and for countries technologically more advanced than the threshold level $\hat{n}$, a cuddly reward structure is preferred and the asymmetric equilibrium emerges.

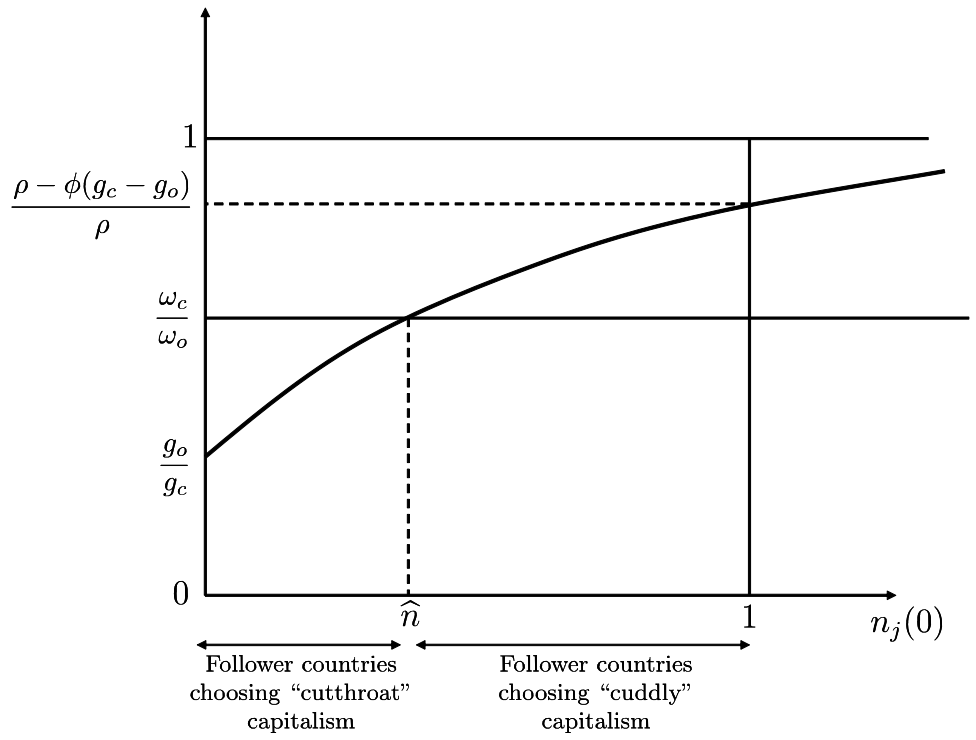

Figure 4: Choice of cutthroat and cuddly reward structures as a function of technology gap $n_{j}(0)$.

We next provide a simpler sufficient condition that enables us to reach the same conclusion as in Proposition 2.

\footnotetext{
${ }^{23}$ We will see in the next section that this economic force will sometimes lead to a time-varying reward structure.
} 
Corollary 1 1. The condition

$$
\left(\frac{\omega_{c}}{\omega_{o}}\right)^{\frac{1}{1-\theta}}<\left(\frac{g_{o}}{g_{c}}\right)^{\frac{1}{\phi}}
$$

is sufficient for (16) to hold, so under this condition and the remaining hypotheses of Proposition 1, the conclusions in Proposition 1 hold.

2. In addition, there exists $\bar{n}$ such that for $n_{j}(0)<\bar{n}$, the condition

$$
\left(\frac{\omega_{c}}{\omega_{o}}\right)^{\frac{1}{1-\theta}}<\left(\frac{g_{o}}{g_{c}}\right)^{\frac{1}{\phi}}\left[1+\frac{n_{j}(0)^{\phi}}{\phi}\left(\rho-(1-\theta) g_{c}\right)\left(\frac{1}{g_{o}}-\frac{1}{g_{c}}\right)\right]^{\frac{1}{1-\theta}}
$$

is sufficient for (16) to hold, so under this condition and the remaining hypotheses of Proposition 1, the conclusions in Proposition 1 hold.

Proof. We first proved the second part of the corollary. By integration by parts,

$$
\begin{aligned}
& \int_{0}^{\infty} e^{-\rho t}\left(e^{\phi g_{c} t}-1\right)^{\frac{1-\theta}{\phi}} d t=\left[-\frac{e^{-\rho t}}{\rho}\left(e^{\phi g_{c} t}-1\right)^{\frac{1-\theta}{\phi}}\right]_{0}^{\infty}+\int_{0}^{\infty} \frac{e^{-\rho t}}{\rho}(1-\theta) e^{\phi g_{c} t} g_{c}\left(e^{\phi g_{c} t}-1\right)^{\frac{1-\theta}{\phi}-1} d t \\
& =\frac{\int_{0}^{\infty} e^{-\rho t}\left(e^{\phi g_{c} t}-1\right)^{\frac{1-\theta}{\phi}-1} d t}{\frac{\rho-(1-\theta) g_{c}}{(1-\theta) g_{c}}} .
\end{aligned}
$$

Then, a first-order Taylor approximation of (15) for $n_{j}(0) \equiv N_{j}(0) / N_{l}(0)$ small gives

$$
\begin{aligned}
\mathcal{W}_{j}\left(s_{j}\right) & \left.=\int_{0}^{\infty} e^{-\rho t} \omega_{s_{j}} N_{\ell}(0)\right)^{1-\theta}\left[\left(\frac{g_{s_{j}}}{g_{c}}\left(e^{\phi g_{c} t}-1\right)\right)^{\frac{1-\theta}{\phi}}+\frac{1-\theta}{\phi} n_{j}(0)^{\phi}\left(\frac{g_{s_{j}}}{g_{c}}\left(e^{\phi g_{c} t}-1\right)\right)^{\frac{1-\theta}{\phi}-1}\right] d t+\mathcal{R}\left(n_{j}(0)\right) \\
& =\omega_{s_{j}}\left(N_{\ell}(0)^{1-\theta}\left(\frac{g_{s_{j}}}{g_{c}}\right)^{\frac{1-\theta}{\phi}}\left(1+\frac{n_{j}(0)^{\phi}}{\phi} \frac{\rho-(1-\theta) g_{c}}{g_{s_{j}}}\right) \int_{0}^{\infty} e^{-\rho t}\left(e^{\phi g_{c} t}-1\right)^{\frac{1-\theta}{\phi}} d t+\mathcal{R}\left(n_{j}(0)\right)\right.
\end{aligned}
$$

where $\mathcal{R}\left(n_{j}(0)\right)$ is the residual which goes to zero as $n_{j}(0) \rightarrow 0$. Thus there exists $\bar{n}>0$ such that for $n_{j}(0)<\bar{n}, \mathcal{W}_{j}(c)<\mathcal{W}_{j}(o)$ if

$$
\left(\frac{\omega_{c}}{\omega_{o}}\right)^{\frac{1}{1-\theta}}<\left(\frac{g_{o}}{g_{c}}\right)^{\frac{1}{\phi}}\left(\frac{1+\frac{n_{j}(0)^{\phi}}{\phi} \frac{\rho-(1-\theta) g_{c}}{g_{o}}}{1+\frac{n_{j}(0)^{\phi}}{\phi} \frac{\rho-(1-\theta) g_{c}}{g c}}\right)^{\frac{1}{1-\theta}} .
$$

Next another first-order Taylor approximation of the right-hand side of this expression gives (18), and with the same reasoning implies that there exists some $0<\tilde{n} \leq \bar{n}$ such that for $n_{j}(0)<\tilde{n}, \mathcal{W}_{j}(c)<\mathcal{W}_{j}(o)$ if $(18)$ holds.

The second part now follows by setting $n_{j}(0)=0$, and noting that in the right-hand side of (16), the term in large parentheses (the ratio of the two integrals) is always greater than 1 , so that $\left(\frac{\omega_{c}}{\omega_{o}}\right)^{\frac{1}{1-\theta}}<\left(\frac{g_{o}}{g_{c}}\right)^{\frac{1}{\phi}}$ is a sufficient condition for all $n_{j}(0)$.

We next provide a simple result characterizing when Condition 1 (which ensures that the leader prefers a cutthroat reward structure) and (18) (which ensures that followers choose a cuddly reward structure) are simultaneously satisfied. This result illustrates the role of risk aversion in the asymmetric equilibria described above. ${ }^{24}$

\footnotetext{
${ }^{24}$ Recall, however, that (18) is a sufficient condition — not the exact condition - for such a symmetric equilibria to exist.
} 
Corollary 2 1. Condition (18) is satisfied for $\gamma \in(0, \bar{\gamma})$ (where $\left.\bar{\gamma} \equiv 1-\sqrt{\frac{q_{0}\left(1-q_{0}\right)}{q_{1}\left(1-q_{1}\right)}}\right)$ and $\theta \geq \theta^{*}(\phi, \gamma)$ where $\bar{\gamma}>0$ and $0<\theta^{*}(\phi, \gamma)<\infty$. Moreover $\theta^{*}(\phi, \gamma)$ is decreasing in $\phi$ and $\gamma$.

2. Condition 1 is satisfied for $\theta \in[0, \bar{\theta}]$ and $\rho \in\left(\bar{\rho}(\theta, \gamma),(1-\theta) g_{c}\right)$, where $\bar{\theta}>0$. Moreover $\bar{\rho}(\theta, \gamma)$ is decreasing in $\theta$ and in $\gamma$.

Proof. See the Appendix.

Therefore, this corollary implies that, under the specified conditions, the asymmetric equilibrium will arise (or more accurately, the sufficient conditions for an asymmetric equilibria will be satisfied) when $\theta \geq \theta^{*}(\phi, \gamma)$, i.e., when the coefficient of relative risk aversion is sufficiently high. But to ensure Assumption 2 also holds, this coefficient needs to be less than some threshold $\bar{\theta}>1$. Note, however, that as $\phi$ increases (so that there are greater technology spillovers from the leader to followers), $\theta^{*}(\phi, \gamma)$ decreases, making these conditions more likely to be satisfied. Naturally, as the second part of the corollary specifies, we also need $\rho$ not to be too small, otherwise it would not be a best response for the technology leader to choose a cutthroat reward structure. Though intuitive, this corollary suffers from the feature that changes in $\theta$ not only correspond to changes in the coefficient of relative risk aversion but also to changes in the intertemporal elasticity of substitution. For this reason, the next subsection considers the more general preferences in (8) which separate these two parameters.

Remark 1 We have so far restricted countries to choose either cutthroat or cuddly reward structures for all of their entrepreneurs. In the next section, we allow for mixed reward structures whereby some entrepreneurs are given incentives to exert high effort, while others are not. It is straightforward to see that in this case, (16) continues to be sufficient, together with Assumptions $1-3$, for there not to exist a symmetric equilibrium, but is no longer necessary. Sufficiency follows simply from the following observation: condition (16) implies that for followers a cuddly reward structure is preferred to a cutthroat one, so even when intermediate reward structures are possible, the equilibrium will not involve a cutthroat reward structure, hence will not be symmetric. The reason why (16) is not necessary is that when $\phi>1-\theta$, welfare is concave in the fraction of agents receiving cutthroat incentives (as we show in the next section), and thus even if a cuddly reward structure is not preferred to a cutthroat one, an intermediate one may be. In particular, denoting the fraction of entrepreneurs receiving cutthroat incentives by $u$, the necessary condition for the follower to adopt a cuddly reward structure is

$$
\begin{aligned}
\frac{\partial \mathcal{W}_{j}(u=0)}{\partial u}= & \left(\omega_{c}-\omega_{o}\right) \int_{0}^{\infty} e^{-\rho t}\left(n_{j}(0)^{\phi}+e^{\phi g_{c} t}-1\right)^{\frac{1-\theta}{\phi}} d t \\
+ & \frac{(1-\theta) \omega_{c}\left(g_{c}-g_{o}\right)}{\phi g_{c}} \int_{0}^{\infty} e^{-\rho t}\left(n_{j}(0)^{\phi}+\left(e^{\phi g_{c} t}-1\right)\right)^{\frac{1-\theta}{\phi}-1}\left(e^{\phi g_{c} t}-1\right) d t<0 .
\end{aligned}
$$

We can also note that under Assumptions 1 and 2 and Condition 1, there cannot be a fully mixed reward structure equilibrium where all countries choose a fraction $u^{*}$ of entrepreneurs to 
receive cutthroat incentives. Suppose that all countries, except the technology leader, choose a mixed reward structure with the fraction $u^{*}$ of entrepreneurs receiving cutthroat incentives. If the leader also chose $u^{*}$, it would remain the leader forever, with discounted utility of

$$
\mathcal{W}_{\ell}\left(u^{*}\right)=\frac{\omega_{c} u^{*}+\omega_{o}\left(1-u^{*}\right)}{\rho-(1-\theta)\left(g_{c} u^{*}+g_{o}\left(1-u^{*}\right)\right)}
$$

which is strictly increasing in $u^{*}$, so that the leader would in fact prefer fully cutthroat rewards.

\subsection{The Effects of Risk Aversion}

To study the effects of risk aversion, we first show that the results derived so far apply with the Epstein-Zin preferences for this social planner as in (8) (Epstein and Zin, 1989). To do this, we first need to modify Assumption 2 and Condition 1 by substituting for $\lambda$ instead of $\theta$ (since it is the intertemporal elasticity of substitution that matters in this case):

\section{Assumption $2^{\prime}$ :}

$$
\rho-(1-\lambda) g_{c}>0
$$

\section{Condition 1':}

$$
\left(\frac{\omega_{c}}{\omega_{o}}\right)^{\frac{1}{1-\theta}}>\left[\frac{\rho-(1-\lambda) g_{c}}{\rho-(1-\lambda) g_{o}}\right]^{\frac{1}{1-\lambda}} .
$$

We can then establish a generalization of Proposition 2 that applies with social planner preferences given by (8).

Proposition 3 Suppose that each country chooses a time-invariant reward structure at time $t=0$. Suppose also that country social planners maximize (8); the world technology frontier is given by (5); Assumptions 1 and $2^{\prime}$ and Condition $1^{\prime}$ hold; and

$$
\left(\frac{\omega_{c}}{\omega_{o}}\right)^{\frac{1}{1-\theta}}<\left(\frac{g_{o}}{g_{c}}\right)^{\frac{1}{\phi}}\left(\frac{\int_{0}^{\infty} e^{-\left(\rho-(1-\lambda) g_{c}\right) t}\left(1+\left(\frac{g_{c}}{g_{o}} n_{j}(0)^{\phi}-1\right) e^{-\phi g_{c} t}\right)^{\frac{1-\lambda}{\phi}} d t}{\int_{0}^{\infty} e^{-\left(\rho-(1-\lambda) g_{c}\right) t}\left(1+\left(n_{j}(0)^{\phi}-1\right) e^{-\phi g_{c} t}\right)^{\frac{1-\lambda}{\phi}} d t}\right)^{\frac{1}{1-\lambda}} \text { for each } j \neq \ell
$$

Then there exists no symmetric equilibrium. Moreover, there exists a unique world equilibrium in which the initial technology leader, country $\ell$ remains so throughout, and this equilibrium involves country $\ell$ choosing a cutthroat reward structure, while all other countries choose a cuddly reward structure. In this world equilibrium, country $\ell$ grows at the rate $g_{c}$ throughout, while all other countries asymptotically grow also at this rate, and converge to a level of income equal to a fraction $g_{o} / g_{c}$ of the level of income of country $\ell$. 
Proof. The proof is essentially identical to that of Proposition 2 after noting that with (8), following the same steps as above, welfare is given by:

$$
\begin{aligned}
\mathcal{W}_{j}\left(s_{j}\right) & =\left[\int_{0}^{\infty} e^{-\rho t}\left(W_{j}^{s_{j}}(t)\right)^{\frac{1-\lambda}{1-\theta}} d t\right]^{\frac{1}{1-\lambda}} \\
& =\omega_{s_{j}}^{\frac{1}{1-\theta}} N_{\ell}(0)\left(\frac{g_{s_{j}}}{g_{c}}\right)^{\frac{1}{\phi}}\left[\int_{0}^{\infty} e^{-\left(\rho-(1-\lambda) g_{c}\right) t}\left(1+\left(\frac{g_{c}}{g_{s_{j}}} n_{j}(0)^{\phi}-1\right) e^{-\phi g_{c} t}\right)^{\frac{1-\lambda}{\phi}} d t\right]^{\frac{1}{1-\lambda}} .
\end{aligned}
$$

Therefore, with the more general Epstein-Zin preferences given in (8), Proposition 2 remains essentially unchanged except that $\lambda$, as the inverse of the intertemporal elasticity of substitution, replaces $\theta$ in the integrals. This also immediately implies that Corollary 1 also applies in this case and we do not state it to save space. The more interesting implication of these more general preferences arises when we turn to the implications of changes in the coefficient of relative risk aversion. The following corollary strengthens Corollary 2 and shows that asymmetric equilibria are more likely to arise for intermediate values of the coefficient of relative risk aversion.

Corollary 3 Suppose $\gamma \leq \bar{\gamma} \equiv 1-\sqrt{\frac{q_{0}\left(1-q_{0}\right)}{q_{1}\left(1-q_{1}\right)}}$. Then Conditions $1^{\prime}$ and (20) are jointly satisfied for intermediate values of the coefficient of relative risk aversion $\theta$.

Proof. Conditions $1^{\prime}$ and (20) are jointly satisfied if

$$
\left(\frac{\rho-(1-\lambda) g_{c}}{\rho-(1-\lambda) g_{o}}\right)^{\frac{1}{1-\lambda}}<\left(\frac{\omega_{c}}{\omega_{o}}\right)^{\frac{1}{1-\theta}}<\left(\frac{g_{o}}{g_{c}}\right)^{\frac{1}{\phi}}\left(\frac{\int_{0}^{\infty} e^{-\left(\rho-(1-\lambda) g_{c}\right) t}\left(1+\left(\frac{g_{c}}{g_{o}} n_{j}(0)^{\phi}-1\right) e^{-\phi g_{c} t}\right)^{\frac{1-\lambda}{\phi}} d t}{\int_{0}^{\infty} e^{-\left(\rho-(1-\lambda) g_{c}\right) t}\left(1+\left(n_{j}(0)^{\phi}-1\right) e^{-\phi g_{c} t}\right)^{\frac{1-\lambda}{\phi}} d t}\right)^{\frac{1}{1-\lambda}}
$$

Only the middle term depends on $\theta$. Straightforwardly, this term is decreasing in $\theta$ for given $A$ and also decreasing in $A$. Moreover, as shown in the proof of Corollary 2, $A$ is decreasing in $\theta$ for $\gamma \leq \bar{\gamma}$. Thus $\left(\frac{\omega_{c}}{\omega_{o}}\right)^{\frac{1}{1-\theta}}$ is monotonically decreasing in $\theta$. Furthermore, $\lim _{\theta \rightarrow \theta_{\max }}\left(\frac{\omega_{c}}{\omega_{o}}\right)^{\frac{1}{1-\theta}}=0$ for $\theta_{\max } \equiv 1-\frac{\log \left(\frac{1-q_{0}}{1-q_{1}}\right)}{\log (1-\gamma)}>1$, establishing the corollary.

This result is intuitive: if the coefficient of relative risk aversion is too high, then no country, not even those at the frontier, would adopt cutthroat incentives, and if there is very limited risk aversion, then all countries are more likely to choose cutthroat incentives.

To gain further intuition, we can again plot the equivalent of the right-hand side of (17), but now under the restriction that $\phi=1-\lambda$, which leaves the coefficient of relative risk aversion, $\theta$, free. In particular, the equivalent of (17) is now:

$$
\left(\frac{\omega_{c}}{\omega_{o}}\right)^{\frac{1}{1-\theta}}<\left(\frac{\left(\rho-\phi g_{c}\right) n_{j}(0)^{\phi}+\phi g_{o}}{\left(\rho-\phi g_{c}\right) n_{j}(0)^{\phi}+\phi g_{c}}\right)^{\frac{1}{\phi}}
$$

The next figure plots the left and right-hand sides of (21) and also illustrates that now an increase in risk aversion (an increase in $\theta$ ) shifts the left-hand side up (again presuming that $\gamma \leq \bar{\gamma}$ ), expanding the set of technology gaps at which the asymmetric equilibrium arises. 


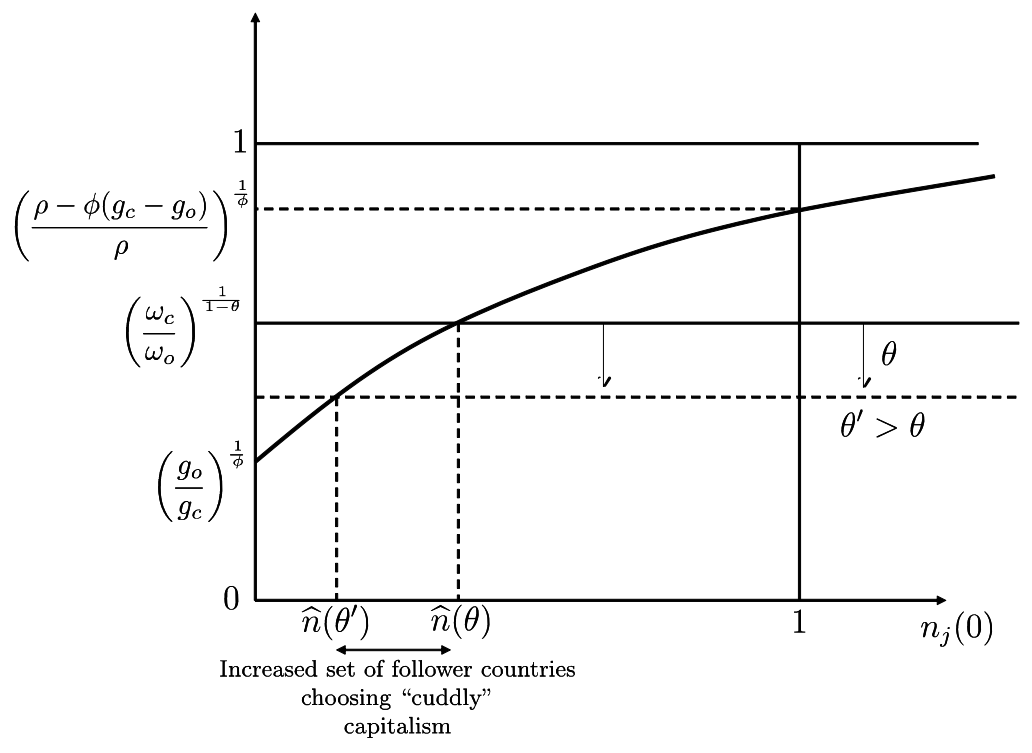

Figure 5: The effect of risk aversion on equilibrium reward structure with Epstein-Zin preferences.

\subsection{Welfare}

The most interesting result concerning welfare is that, even though the technological leader, country $\ell$, starts out ahead of others and chooses a "growth-maximizing" strategy, average welfare (using the social planner's discount rate) may be lower in that country than in the followers choosing a cuddly reward structure. This result is contained in the next proposition and its intuition captures the central economic force of our model: followers are both able to choose an egalitarian reward structure providing perfect insurance to their entrepreneur/workers and benefit from the rapid growth of technology driven by the technology leader, country $\ell$, because they are able to free-ride on the cutthroat reward structure in country $\ell$, which is advancing the world technology frontier. In contrast, country $\ell$, as the technology leader, must bear the cost of high risk for its entrepreneur/workers. The fact that followers prefer to choose the cuddly reward structure implies that, all else equal, the leader, country $\ell$, would have also liked to but cannot do so, because it realizes that if it did, the growth rate of world technology frontier would slow down - while followers know that the world technology frontier is being advanced by country $\ell$ and can thus free-ride on that country's cutthroat reward structure.

Proposition 4 Suppose that countries are restricted to time-invariant reward structures, and Condition 1 and (16) (or Condition $1^{\prime}$ and (20)) hold, so that country $\ell$ adopts the cutthroat strategy and country $j$ adopts the cuddly strategy. Then their exists $\delta>0$ such that for all $n_{j}(0)>1-\delta$, welfare in country $j$ is higher than welfare in country $\ell$.

Proof. Consider the case where $n_{\ell}(0)=n_{j}(0)$. Then the result follows immediately from (16) (or $(20)$ ), since, given this condition, country $j$ strictly prefers to choose a cuddly rather than a 
cutthroat reward structure. If it were to choose a cutthroat structure, it would have exactly the same welfare as country $\ell$. Next by continuity, this is also true for $n_{j}(0)>1-\delta$ for $\delta$ sufficiently small and positive.

\section{Equilibrium with Time-Varying Rewards Structures}

In this section, we relax the assumption that reward structures are time-invariant, and thus assume that each country chooses $s_{j}(t) \in\{c, o\}$ at time $t$, given the strategies of other countries, thus defining a differential game among the $J$ countries. We focus on the Markov perfect equilibria of this differential game, where strategies at time $t$ are only conditioned on payoff relevant variables, given by the vector of technology levels. To start with, we focus on the world technology frontier given by (5), and at the end, we will show that the most important insights generalize to the case with general aggregators of the form (6) provided that these aggregators are sufficiently "convex," i.e., putting more weight on technologically more advanced countries. Throughout this section, we also suppose that country social planners maximize (7).

\subsection{Main Result}

In this subsection, we focus on the world technology frontier given by (5), and also assume that at the initial date, there exists a single country $\ell$ that is the technology leader, i.e., a single $\ell$ for which $N_{\ell}(0)=\max \left\{N_{1}(0), \ldots, N_{J}(0)\right\}$. We also allow follower countries to provide cutthroat reward structures to some of their entrepreneurs while choosing a cuddly reward structure for the rest. Hence, we define $u_{j}(t)$ as the fraction of entrepreneurs receiving a cutthroat reward structure, ${ }^{25}$ and thus

$$
\begin{aligned}
\omega\left(u_{j}(t)\right) & =\omega_{o}\left(1-u_{j}(t)\right)+\omega_{c} u_{j}(t) \\
g\left(\left(u_{j}(t)\right)\right. & =g_{o}\left(1-u_{j}(t)\right)+g_{c} u_{j}(t),
\end{aligned}
$$

with $u_{j}(t) \in[0,1]$, and $u_{j}(t)=0$ at all points in time corresponds to a cuddly reward structure and $u_{j}(t)=1$ for all time is cutthroat throughout, like those analyzed in the previous section.

The problem of the country $j$ social planner can then be written as

$$
\begin{aligned}
\mathcal{W}_{j}\left(N_{j}(t), N_{\ell}(t)\right) & =\max _{u_{j}(\cdot) \in[0,1]} \int_{t}^{\infty} e^{-\rho(\tau-t)} \omega\left(u_{j}(\tau)\right) N_{j}(\tau)^{1-\theta} d \tau \\
\text { such that } \dot{N}_{j}(\tau) & =g\left(\left(u_{j}(\tau)\right) N_{\ell}(\tau)^{\phi} N_{j}(\tau)^{1-\phi}\right. \\
\text { with } N_{\ell}(\tau) & =N(t) e^{g_{c}(\tau-t)}(\text { for } \tau \geq t) .
\end{aligned}
$$

Depending on what the country $j$ social planner can condition on for the choice of time $t$ reward structure, this would correspond to either a "closed loop" or "open loop" problem - i.e., one in which the strategies are chosen at the beginning or are updated as time goes by. In the

\footnotetext{
${ }^{25}$ It is straightforward to see that it is never optimal to give any entrepreneur any other reward structures than perfect insurance or the cutthroat reward structure that satisfies the incentive compatibility constraint as equality
} 
Appendix, we show that the two problems have the same solution, so the distinction is not central in this case. The main result in this section is as follows.

Proposition 5 Suppose country social planners maximize (7), the world technology frontier is given by (5), Condition 1 holds, and technology spillovers are large in the sense that $\phi>1-\theta$. Let

$$
\widetilde{m} \equiv(1-\theta) \frac{\left(\omega_{o}-\omega_{c}\right) g_{c}+\left(g_{c}-g_{o}\right) \omega_{c}}{\left(\omega_{o}-\omega_{c}\right)\left(\rho+\phi g_{c}\right)} .
$$

Then the world equilibrium is characterized as follows:

1. If

$$
\widetilde{m}<\frac{g_{o}}{g_{c}}
$$

there exist $\bar{m}<g_{o} / g_{c}$ and $0<T<\infty$ such that for $n_{j}(0)<\bar{m}^{1 / \phi}$, the reward structure of country $j$ is cutthroat (i.e., $s_{j}(t)=c$ or $u_{j}(t)=1$ ) for all $t \leq T$, and cuddly (i.e., $s_{j}(t)=o$ or $\left.u_{j}(t)=0\right)$ for all $t>T$; for $n_{j}(0) \geq \bar{m}^{1 / \phi}$, the reward structure of country $j$ is cuddly (i.e., $s_{j}(t)=o$ or $u_{j}(t)=0$ ) for all $t$. Moreover, $\bar{m}>0$ if $\theta<1$, and $\bar{m}<0$ if $\theta$ is sufficiently large (in which case the cuddly reward structure applies with any initial condition). Regardless of the initial condition (and the exact value of $\bar{m}$ ), in this case, $n_{j}(t) \rightarrow\left(g_{o} / g_{c}\right)^{1 / \phi}$.

2. If

$$
\frac{g_{o}}{g_{c}}<\widetilde{m}<1
$$

there exists $0<T<\infty$ such that for $n_{j}(0)<\widetilde{m}^{1 / \phi}$, the reward structure of country $j$ is cutthroat (i.e., $s_{j}(t)=c$ or $u_{j}(t)=1$ ) for all $t \leq T$, and then at $t=T$ when $n_{j}(T)=\widetilde{m}^{1 / \phi}$, the country adopts a "mixed" reward structure and stays at $n_{j}(t)=\widetilde{m}^{1 / \phi}$ (i.e., $u_{j}(t)=u_{j}^{*} \in(0,1)$ ) for all $t>T$; for $n_{j}(0)>\widetilde{m}^{1 / \phi}$, the reward structure of country $j$ is cuddly (i.e., $s_{j}(t)=o$ or $u_{j}(t)=0$ ) for all $t \leq T$, and then at $t=T$ when $n_{j}(T)=\widetilde{m}^{1 / \phi}$, the country adopts a mixed reward structure and stays at $n_{j}(t)=\widetilde{m}^{1 / \phi}$ (i.e., $u_{j}(t)=u_{j}^{*} \in(0,1)$ ) for all $t>T$.

3. If

$$
\widetilde{m}>1
$$

then the reward structure of country $j$ is cutthroat for all $t$ (i.e., $s_{j}(t)=c$ or $u_{j}(t)=1$ for all $t)$.

Proof. We prove the more general Proposition 6 in the next section. A different and more direct proof of Proposition 5 is provided in the Appendix.

This proposition has several important implications. First, the equilibrium of the previous section emerges as a special case, in particular when condition (24) holds and the initial gap between the leader and the followers is not too large (i.e., $n_{j}(0)$ is greater than the threshold 
specified in the proposition), or when $\bar{m}<0$. In this case, the restriction to time-invariant reward structures is not binding, and exactly the same insights as in the previous section obtain.

Secondly, however, the rest of the proposition shows that the restriction to time-invariant reward structures is generally binding, and the equilibrium involves countries changing their reward structures over time. In fact, part 1 of the proposition shows that, in line with the discussion following Proposition 2, the growth benefits of cutthroat reward structures are greater when the initial gap between the leader and the country in question is larger, because this creates a period during which this country can converge rapidly to the level of income of the technological leader, and a cutthroat reward structure can significantly increase this convergence growth rate. In consequence, for a range of parameters, the equilibrium involves countries that are sufficiently behind the technological leader choosing cutthroat reward structures, and then after a certain amount of convergence takes place, switching to cuddly capitalism. This pattern, at least from a bird's eye perspective, captures the sort of growth and social trajectory followed by countries such as South Korea and Taiwan, which adopted fairly high-powered incentives with little safety net during their early phases of convergence, but then started building a welfare state.

Thirdly, part 2 shows that without the restriction to time-invariant reward structures, some countries may adopt mixed reward structures when they are close to the income level of the leader. With such reward structures some entrepreneurs are made to bear risk, while others are given perfect insurance - and thus are less innovative. This enables them to reach a growth rate between that implied by a fully cuddly reward structure and the higher growth rate of the cutthroat reward structure.

Finally, for another range of parameters (part 3 of the proposition), there is "institutional" and technology convergence in that followers also adopt cutthroat reward structures. When this is the case, technology spillovers ensure not only the same long-run growth rate across all countries but convergence in income and technology levels. In contrast, in other cases, countries maintain their different institutions (reward structures), and as a result, they reach the same growth rate, but their income levels do not converge.

The growth dynamics implied by this proposition are also interesting. These are shown in Figures 6-8. Figure 6 corresponds to the part 1 of Proposition 5, and shows the pattern where, starting with a low enough initial condition, i.e., $n_{j}(0)<\bar{m}^{1 / \phi}$, cutthroat capitalism is followed by cuddly capitalism. As the figure shows, when $n_{j}(t)$ reaches $\bar{m}^{1 / \phi}$, the rate of convergence changes because there is a switch from cutthroat to cuddly capitalism. This figure also illustrates another important aspect of Proposition 5: there is institutional divergence as a country converges to the technological leader - and as a consequence of this, this convergence is incomplete, i.e., $n_{j}(t)$ converges to $\left(g_{o} / g_{c}\right)^{1 / \phi}$. The figure also shows that countries that start out with $n_{j}(0)>\bar{m}^{1 / \phi}$ will choose cuddly capitalism throughout.

Figure 7 shows the somewhat different pattern of convergence implied by part 2 of the proposition, where followers reach the growth rate of the leader in finite time and at a higher level of relative income - because they choose a mixed reward structure in the limit. Nevertheless, insti- 


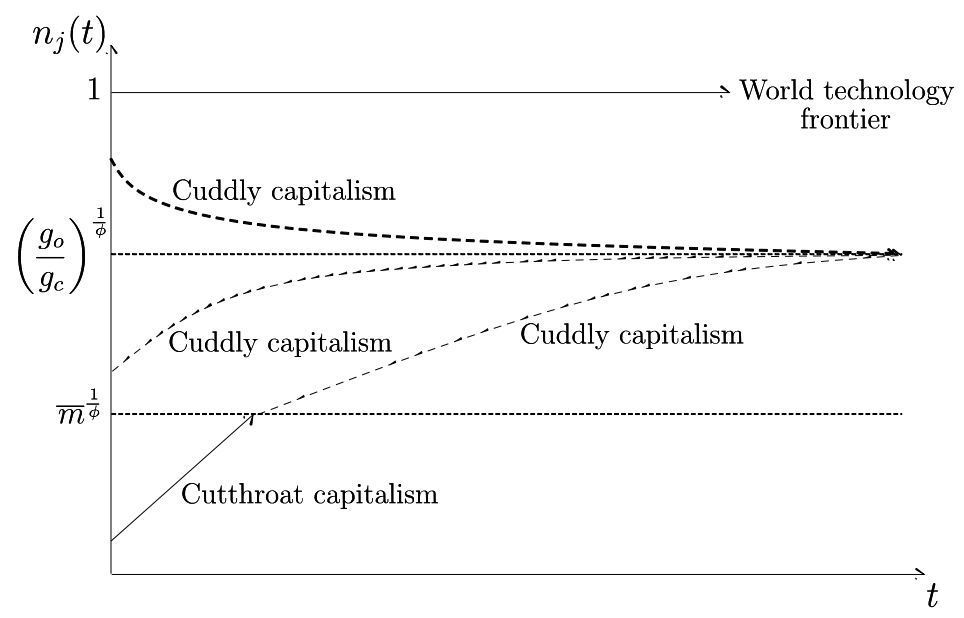

Figure 6: Growth dynamics: part 1 of Proposition 5

tutional and level differences between the leader and followers remain. In Figure 8 corresponding to part 3, leaders and followers adopt the same institutions and there is complete convergence.

\subsection{Time-Varying Reward Structures With Epstein-Zin Preferences}

In this subsection, we show that a variant of Proposition 5 holds with the preferences given in (8). Our main result in this subsection is presented in the next proposition, and because the proof illustrates the growth dynamics in a complementary manner to Proposition 5, we provide it in the text.

Proposition 6 Suppose country social planners maximize (8), the world technology frontier is given by (5), Assumptions 1 and $2^{\prime}$, and Condition $1^{\prime}$ hold, and technology spillovers are large in the sense that $\phi>1-\theta$. Suppose also that either $\theta<\lambda<1$ or $\theta>\lambda>1$. Let

$$
\widetilde{m_{o}} \equiv \frac{(1-\theta) \omega_{o}\left(g_{c}-g_{o}\right)+(1-\lambda) g_{o}\left(\omega_{o}-\omega_{c}\right)}{\left(\rho+\phi g_{c}\right)\left(\omega_{o}-\omega_{c}\right)}
$$

and

$$
\widetilde{m_{c}} \equiv \frac{(1-\theta) \omega_{c}\left(g_{c}-g_{o}\right)+(1-\lambda) g_{c}\left(\omega_{o}-\omega_{c}\right)}{\left(\rho+\phi g_{c}\right)\left(\omega_{o}-\omega_{c}\right)} .
$$

Then the world equilibrium is characterized as follows:

1. If

$$
\frac{g_{o}}{g_{c}}>\widetilde{m_{o}}>\widetilde{m_{c}}
$$

there exist $\underline{\underline{m}}, \underline{m}, T$ and $T^{\prime}$ such that for $n_{j}(0)<\underline{\underline{m}}^{1 / \phi}$, the reward structure of country $j$ is cutthroat (i.e., $s_{j}(t)=c$ or $u_{j}(t)=1$ ) for all $t \leq T$, and then at $t=T$, we have $n_{j}(T)=$ $\underline{\underline{m}}^{1 / \phi}$ and country $j$ adopts a "mixed" reward structure until $T^{\prime}\left(i . e ., u_{j}(t) \in(0,1)\right)$ for all 


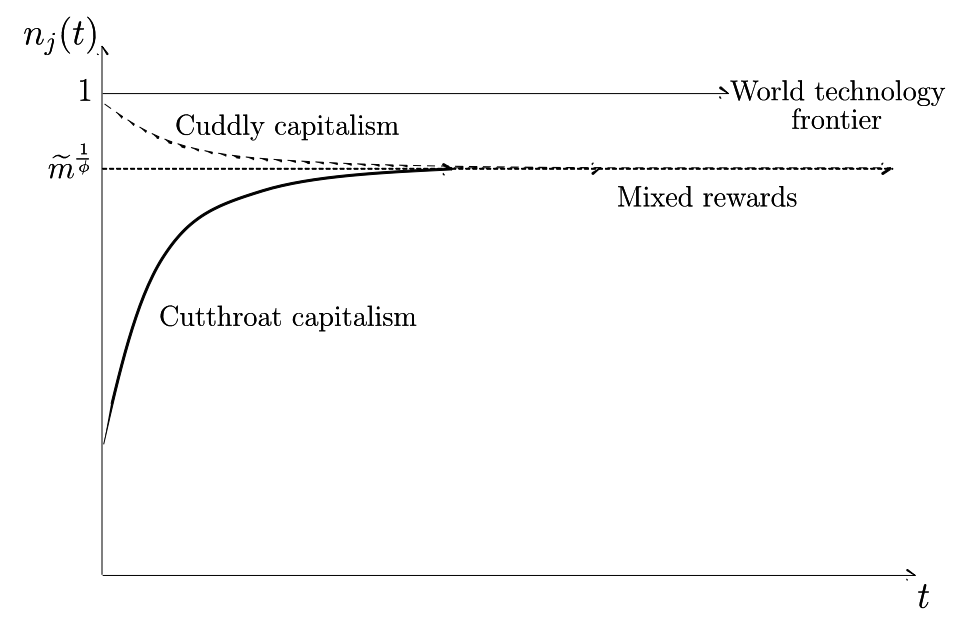

Figure 7: Growth dynamics: part 2 of Proposition 5

$T^{\prime}>t>T$. Then at $t=T^{\prime}$, we have $n_{j}\left(T^{\prime}\right)=\underline{m}^{1 / \phi}$ and country $j$ switches to a cuddly reward structure (i.e., $s_{j}(t)=$ o or $u_{j}(t)=0$ ) for all $t \geq T^{\prime}$, and $n_{j}(t) \rightarrow\left(g_{o} / g_{c}\right)^{1 / \phi}$.

2. If

$$
\frac{g_{o}}{g_{c}}<\widetilde{m_{o}} \text { and } 1>\widetilde{m_{c}}
$$

then there exist $\underline{\underline{m}}$ and $\underline{m}$ such that for $\underline{m}^{1 / \phi}<n_{j}(0)<\underline{\underline{m}}^{1 / \phi}$, the reward structure of country $j$ is mixed (i.e., $u_{j}(t) \in(0,1)$ ) for all $t$, and $\left(m_{j}(t), u_{j}(t)\right) \rightarrow\left(m^{*}, u^{*}\right)$. If $n_{j}(0)<\underline{\underline{m}}^{1 / \phi}$, then country $j$ first adopts a cutthroat reward structure (i.e., $s_{j}(t)=c$ or $\left.u_{j}(t)=1\right)$ until some $T$, and then switches to a mixed reward structure, again converging to a unique $\left(m^{*}, u^{*}\right)$, and if $n_{j}(0)>\underline{m}^{1 / \phi}$, then country $j$ first adopts a cuddly reward structure (i.e., $s_{j}(t)=o$ or $u_{j}(t)=0$ ) until some $T^{\prime}$, and then switches to a mixed reward structure, again converging to a unique $\left(m^{*}, u^{*}\right)$.

3. If

$$
\widetilde{m_{o}}>\widetilde{m_{c}}>1
$$

then for any $n_{j}(0)<1$, the reward structure of country $j$ is cutthroat for all $t$ (i.e., $s_{j}(t)=c$ or $u_{j}(t)=1$ for all $\left.t\right)$.

Proof. Now the optimization problem for a follower country, dropping the $j$ subscript, can be written as

$$
\begin{aligned}
& \max _{u(t)} \int_{0}^{\infty} e^{-\rho t} w(u(t))^{\frac{1-\lambda}{1-\theta}} m(t)^{\frac{1-\lambda}{\phi}} N_{\ell}(t)^{1-\lambda} d t \quad \text { s.t: } \quad \dot{m}(t)=\phi\left[g(u(t))-g_{c} m(t)\right], \\
& \dot{N}_{\ell}(t)=g_{c} N_{\ell}(t) \\
& m(0)=\left(N(0) / N_{\ell}(0)\right)^{\phi} \text { given. }
\end{aligned}
$$




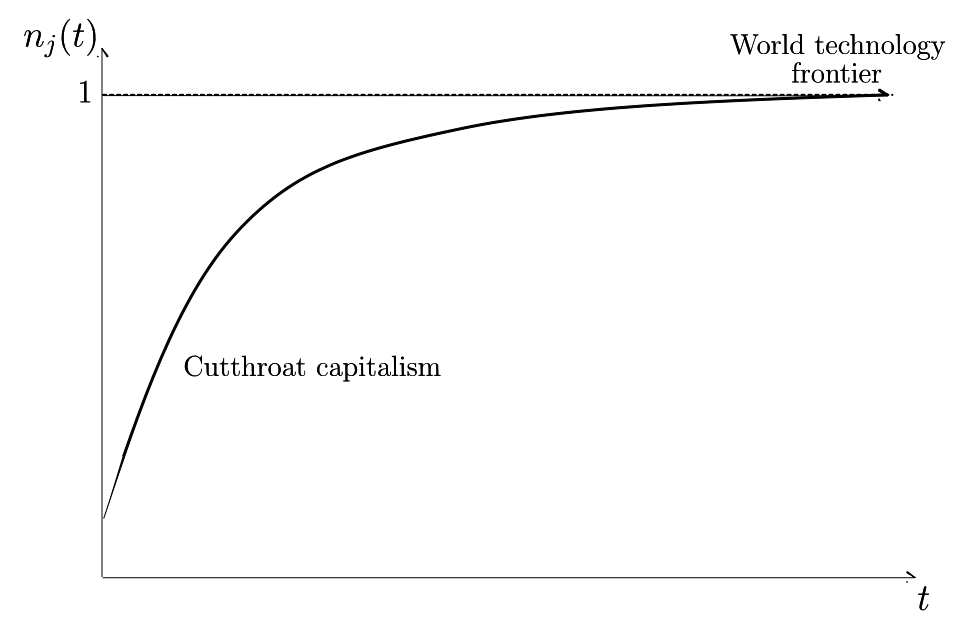

Figure 8: Growth dynamics: part 3 of Proposition 5

Here, $u(t) \in[0,1]$ is again the fraction of entrepreneurs receiving cutthroat incentives, and $m(t) \equiv\left(N(t) / N_{\ell}(t)\right)^{\phi}$. Now substituting for $N_{\ell}$, this is equivalent to:

$$
\max _{u(t)} \int_{0}^{\infty} e^{-\left(\rho-(1-\lambda) g_{c}\right) t} w(u(t))^{\frac{1-\lambda}{1-\theta}} m(t)^{\frac{1-\lambda}{\phi}} d t \quad \text { s.t: } \quad \begin{gathered}
\dot{m}(t)=\phi\left[g(u(t))-g_{c} m(t)\right], \\
m(0)=\left(N(0) / N_{\ell}(0)\right)^{\phi} \text { given } .
\end{gathered}
$$

The current value Hamiltonean for this problem can be written as

$$
H=w(u(t))^{\frac{1-\lambda}{1-\theta}} m(t)^{\frac{1-\lambda}{\phi}}+\mu(t) \phi\left[g(u(t))-g_{c} m(t)\right],
$$

which is strictly concave in $m$ when $\phi>1-\lambda$, and strictly concave in $u$ when $1>\lambda>\theta$ or $\theta>\lambda>1$.

Consider the candidate solution given by the Maximum Principle, i.e., as a solution to the following equations:

$$
\begin{aligned}
\frac{\partial H}{\partial u} & =\Psi(t) \equiv \frac{1-\lambda}{1-\theta}\left(\omega_{c}-\omega_{o}\right) \omega(u(t))^{\frac{\theta-\lambda}{1-\theta}} m(t)^{\frac{1-\lambda}{\phi}}+\mu(t) \phi\left(g_{c}-g_{o}\right)=0 \text { for } 0 \leq u(t) \leq 1 \\
\dot{m}(t) & =\phi\left[g(u(t))-g_{c} m(t)\right] \\
\dot{\mu}(t) & =\left(\rho-(1-\lambda) g_{c}+\phi g_{c}\right) \mu(t)-\frac{1-\lambda}{\phi} \omega(u(t))^{\frac{1-\lambda}{1-\theta}} m(t)^{\frac{1-\lambda}{\phi}-1},
\end{aligned}
$$

together with the transversality condition, not taking the form

$$
\lim _{t \rightarrow \infty} e^{-\left(\rho-(1-\lambda) g_{c}\right) t} \mu(t)=0 .
$$

If the first condition cannot be satisfied for interior $u(t)$, we have a corner solution at 0 or 1 . In particular, substituting for $u(t)=0$, we obtain the following curve in the $(m, \mu)$ space:

$$
\Psi_{0}(t) \equiv \frac{1-\lambda}{1-\theta}\left(\omega_{c}-\omega_{o}\right) \omega_{o}^{\frac{\theta-\lambda}{1-\theta}} m(t)^{\frac{1-\lambda}{\phi}}+\mu(t) \phi\left(g_{c}-g_{o}\right)=0
$$




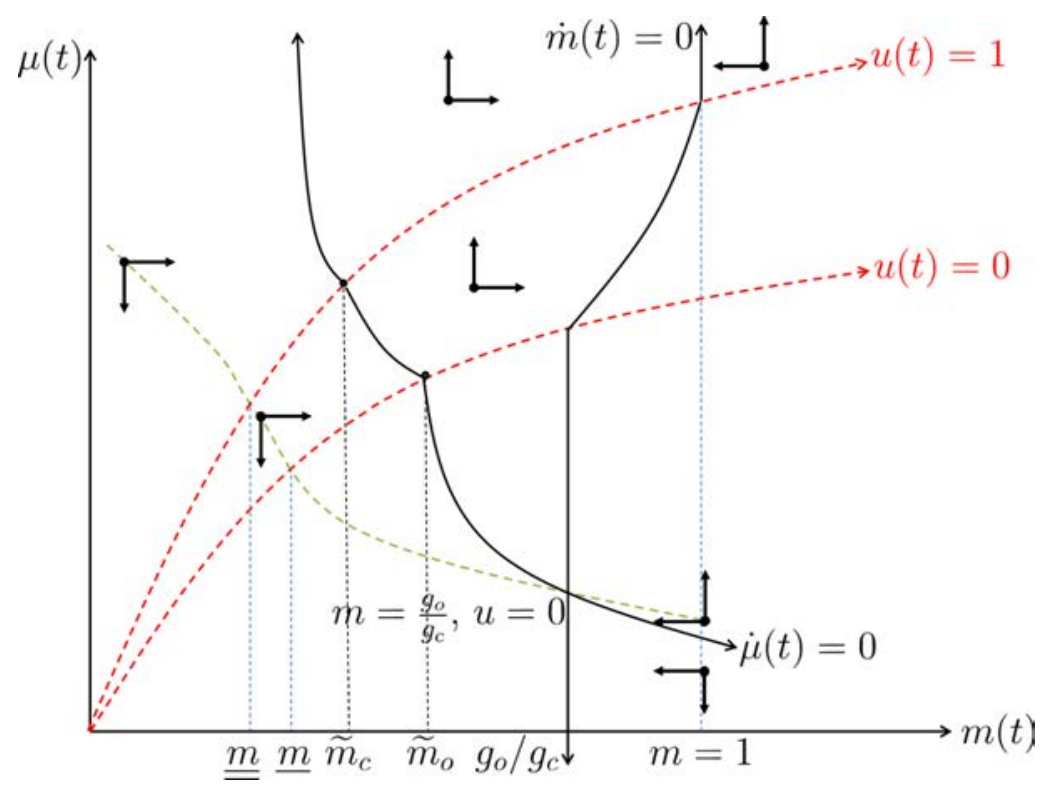

Figure 9: Case 1-Cuddly Reward Structure in the Limit.

and substituting for $u(t)=1$,

$$
\Psi_{1}(t) \equiv \frac{1-\lambda}{1-\theta}\left(\omega_{c}-\omega_{o}\right) \omega_{c}^{\frac{\theta-\lambda}{1-\theta}} m(t)^{\frac{1-\lambda}{\phi}}+\mu(t) \phi\left(g_{c}-g_{o}\right)=0 .
$$

To the right of the first curve shown in Figure 9, the candidate solution involves $u(t)=0$, and to the left of the second curve, $u(t)=1$. In-between, the solution involves mixed rewards. The corresponding rewards can be straightforwardly solved out for

$$
u(t)=-\frac{1}{\omega_{o}-\omega_{c}}\left[\left(\frac{(1-\theta) \mu(t) \phi\left(g_{c}-g_{o}\right)}{(1-\lambda)\left(\omega_{o}-\omega_{c}\right) m(t)^{\frac{1-\lambda}{\phi}}}\right)^{\frac{1-\theta}{\theta-\lambda}}-\omega_{o}\right] .
$$

Substituting this into the above differential equations for $m(t)$ and $\mu(t)$, we obtain two autonomous differential equations in these two variables describing the dynamics with mixed rewards:

$$
\begin{aligned}
& \dot{m}(t)=\phi\left[g_{o}-\frac{\left(g_{c}-g_{o}\right)}{\omega_{o}-\omega_{c}}\left[\left(\frac{(1-\theta) \mu(t) \phi\left(g_{c}-g_{o}\right)}{(1-\lambda)\left(\omega_{o}-\omega_{c}\right) m(t)^{\frac{1-\lambda}{\phi}}}\right)^{\frac{1-\theta}{\theta-\lambda}}-\omega_{o}\right]-g_{c} m(t)\right], \\
& \dot{\mu}(t)=\left(\rho-(1-\lambda) g_{c}+\phi g_{c}\right) \mu(t)-\frac{1-\lambda}{\phi}\left(\frac{(1-\theta) \phi\left(g_{c}-g_{o}\right)}{(1-\lambda)\left(\omega_{o}-\omega_{c}\right)}\right)^{\frac{1-\lambda}{\theta-\lambda}} \mu(t)^{\frac{1-\lambda}{\theta-\lambda}} m(t)^{\frac{\theta(1-\phi)+\lambda-1}{\phi(\theta-1)}} .
\end{aligned}
$$

When these differential equations intersect with the $\Psi_{0}(t)$ and $\Psi_{1}(t)$ curves, then $u(t)$ takes the value 0 or 1 , respectively, and these two differential equations simplify to

$$
\begin{aligned}
\dot{m}(t) & =\phi\left[g_{o}-g_{c} m(t)\right] \\
\dot{\mu}(t) & =\left(\rho-(1-\lambda) g_{c}+\phi g_{c}\right) \mu(t)-\frac{1-\lambda}{\phi} \omega_{o}^{\frac{1-\lambda}{1-\theta}} m(t)^{\frac{1-\lambda}{\phi}-1}
\end{aligned}
$$


or to

$$
\begin{aligned}
\dot{m}(t) & =\phi\left[g_{c}-g_{c} m(t)\right] \\
\dot{\mu}(t) & =\left(\rho-(1-\lambda) g_{c}+\phi g_{c}\right) \mu(t)-\frac{1-\lambda}{\phi} \omega_{c}^{\frac{1-\lambda}{1-\theta}} m(t)^{\frac{1-\lambda}{\phi}-1} .
\end{aligned}
$$

The full system is drawn for case 1 , where $\frac{g_{o}}{g_{c}}>\widetilde{m_{o}}>\widetilde{m_{c}}$, in Figure 9 . In this case, it can be verified that the intersection of the loci for $\dot{m}(t)=0$ and $\dot{\mu}(t)=0$ is indeed at $m=g_{o} / g_{c}$ (corresponding to $\left.n=\left(g_{o} / g_{c}\right)^{1 / \phi}\right)$. The laws of motion plotted in the figure also make it clear that the candidate solution trajectory will start with $s_{j}(t)=c$ or $u_{j}(t)=1$ if $m(0)<\underline{\underline{m}}$ or $n(0)<\underline{\underline{m}}^{1 / \phi}$, and then switch to a mixed reward structure (i.e., $u_{j}(t) \in(0,1)$ ), and then at $m=\underline{m}$ or $n=\underline{m}^{1 / \phi}$, two switch to $s_{j}(t)=o$ or $u_{j}(t)=0$. Throughout $m(t)$ increases monotonically towards $g_{o} / g_{c}$. To complete the proof of the first part, we only need to show that this candidate solution is optimal for the country $j$ planner (and then concavity, combined with the Mangasarian sufficiency condition as in the proof of Proposition 5 in the Appendix, ensures that this is the unique optimal plan). This follows by integrating out $m(t)$ and $\mu(t)$ using (30) to obtain

$$
\Psi(t)=\frac{1-\lambda}{1-\theta}\left(\omega_{o}-\omega_{c}\right) \omega_{o}^{\frac{\theta-\lambda}{1-\theta}} \int_{t}^{\infty} e^{-\left(\rho-(1-\lambda) g_{c}+\phi g_{c}\right) \tau} m(\tau)^{\frac{1-\lambda}{\phi}-1}\left(\widetilde{m}_{o}-m(\tau)\right) d \tau
$$

for $m(t) \geq \underline{m}$. If $u(t)=0$ for all $t$, then we have $m(t) \rightarrow g_{o} / g_{c}$, ensuring that $\Psi(0) \leq 0$. This implies that the above plan is optimal for $m(t) \geq \underline{m}$. Now considering $m(0)<\underline{m}$, only the path shown in the figure avoids a jump and can be optimal. This completes the proof of case 1 .

Next consider case 3. Given the parameter configuration, now the unique intersection of the loci for $\dot{m}(t)=0$ and $\dot{\mu}(t)=0$ is at $m=1$ as shown in Figure 10. The laws of motion in this case also show easily that starting with any $m(0)<1$, the unique solution involves $u(t)=1$ for all $t$, converging to $m=1$. With the same argument invoking the Mangasarian sufficiency condition, this completes the proof of case 3 .

Finally consider case 2 . the intersection of the loci for $\dot{m}(t)=0$ and $\dot{\mu}(t)=0$ is in the interior, mixed rewards range. The laws of motion, depicted in Figure 11, again show that there is a unique trajectory converging to this intersection, which involves mixed reward structure with the fraction $u^{*} \in(0,1)$ of entrepreneurs receiving cutthroat rewards. This completes the proof of the proposition.

First note that the condition that $\theta<\lambda<1$ or $\theta>\lambda>1$ is now imposed to ensure concavity (together with the condition from Proposition 5 that $\phi>1-\theta$ ). Second, this proposition makes it clear that essentially all the substantive results from Proposition 5 generalize to an economy with the more general Epstein-Zin preferences. Inspection shows that the three different cases of Proposition 5 correspond to the three different cases of Proposition 6, and have the same economic content implications. Third, however, both the mathematical argument for establishing these results and the nature of the results are somewhat different. In particular, the transition to mixed rewards in the third case happens smoothly rather than with the jump as in Proposition 5. 


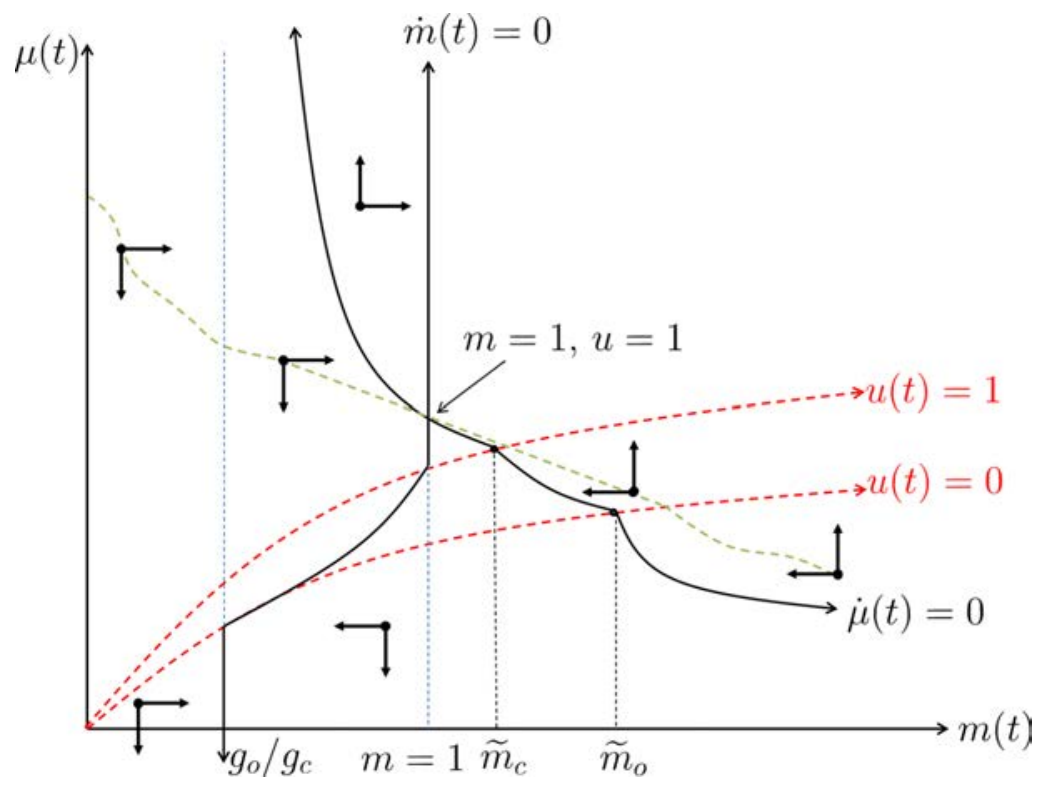

Figure 10: Case 3-Cutthroat Reward Structure Everywhere.

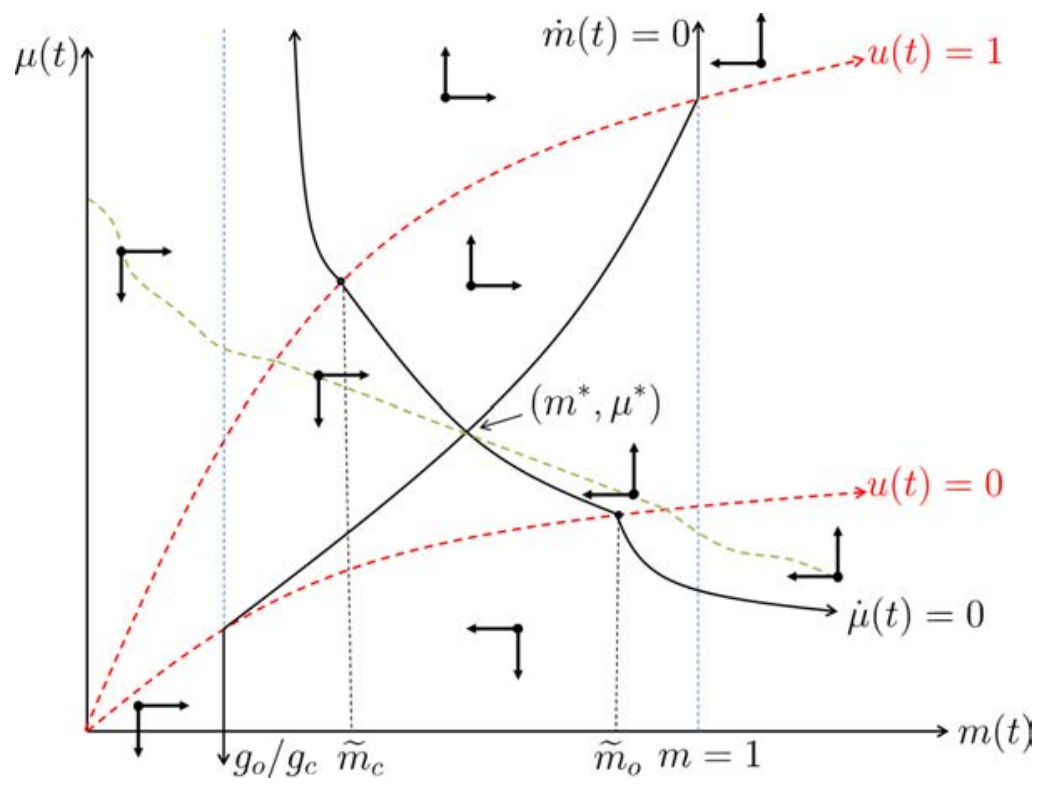

Figure 11: Case 2-Mixed Reward Structure in the Limit. 


\subsection{General Convex Aggregators for World Technology Frontier}

We next show that the main result of this section holds with general aggregators of the form (6) provided that these aggregators are sufficiently "convex," i.e., putting sufficient weight on technologically more advanced countries. The main difference from the rest of our analysis is that with such convex aggregators, the world growth rate is no longer determined by the reward structure (and innovative activities) of a single technology leader, but by a weighted average of all economies. Nevertheless, the same economic forces exhibit themselves because the convexity of these aggregators implies that the impact on the world growth rate of a change in the reward structure of a technologically advanced country would be much larger than that of a backward economy, and this induces the relatively advanced economies to choose cutthroat reward structures, while relatively backward countries can free-ride and choose cuddly reward structures safe in the knowledge that their impact on the long-run growth rate of the world economy (and thus their own growth rate) will be small.

Proposition 7 Suppose that country social planners maximize (7) or (8), and the world technology frontier is given by (6). Then there exist $\bar{\sigma}<0, \bar{\rho}>0$ and $\bar{\gamma}<1$ such that when $\sigma \in(\bar{\sigma}, 0), \rho \leq \bar{\rho}$ and $\bar{\gamma}>\gamma$ there is no symmetric world equilibrium with all countries choosing the same reward structure. Instead, there exists $T<\infty$ such that for all $t>T$, a subset of countries will choose a cutthroat reward structure while the remainder will choose a cuddly or mixed reward structure.

Proof. See the Appendix.

\section{Equilibrium under Domestic Political Constraints}

In this section, we focus on the world economy with two countries, $j$ and $j^{\prime}$, and also simplify the discussion by assuming that $n_{j^{\prime}}(0)=n_{j}(0)$, by focusing on time-invariant reward structures as in Section 3, and also by assuming that the world technology frontier is given by (5) again as in Section 3. This implies that there are two asymmetric equilibria, one in which country $j$ is the technology leader and $j^{\prime}$ the follower, and vice versa. We also suppose that the social planner in country $j$ is subject to domestic political constraints imposed by a labor movement or a social democratic party, which prevent the ratio of rewards when successful and unsuccessful to be more than some amount $\zeta$. There are no domestic constraints in country $j^{\prime}$. If $\zeta \geq A$, then domestic constraints have no impact on the choice of country $j$, and there continue to be two asymmetric equilibria.

Suppose instead that $\zeta<A$. This implies that because of domestic political constraints, it is impossible for country $j$ to adopt a cutthroat strategy regardless of the strategy of country $j^{\prime}$. This implies that of the two asymmetric equilibria, the one in which country $j$ adopts a cutthroat reward structure disappears, and the unique equilibrium (with time-invariant strategies) becomes the one in which country $j^{\prime}$ adopts the cutthroat strategy and country $j$ chooses an egalitarian 
structure. However, from Proposition 5 above, this implies that country $j$ will now have higher welfare than in the other asymmetric equilibrium (which has now disappeared). This simple example thus illustrates how domestic political constraints, particularly coming from the left and restricting the amount of inequality in society, can create an advantage in the world economy.

We next show that this result generalizes to the case in which the two countries do not start with the same initial level of technology. To do this, we relax our focus on equilibria in which the leader at time $t=0$ always remains the leader. Let us also suppose, without loss of any generality, that country $j^{\prime}$ is technologically more advanced at $t=0$, so that $n_{j}(0) \leq 1$. Then we have the following proposition.

Proposition 8 Suppose that country social planners maximize (7) and the world technology frontier is given by (5). Suppose also that there are two countries $j$ and $j^{\prime}$ with initial technology levels $N_{j^{\prime}}(0) \geq N_{j}(0)$ (which is without loss of any generality), they are restricted to timeinvariant reward structures, Condition 1 and (16) hold.

1. There exists $\delta>0$ such that for all $n_{j}(0)>1-\delta$, there are two asymmetric time-invariant equilibria, one in which country $j$ adopts a cutthroat reward structure and country $j^{\prime}$ adopts a cuddly reward structure, and vice versa.

2. If domestic constraints imply that country $j$ cannot adopt a cutthroat reward structure, then the unique time-invariant equilibrium is the one in which country $j^{\prime}$ adopts a cutthroat reward structure and country $j$ adopts a cuddly reward structure. The equilibrium welfare of country $j$ is greater than that of country $j^{\prime}$.

Proof. The first part follows by noting that when Condition 1 holds and the gap between the two countries is small (i.e., $n_{j}(0)>1-\delta$ ), then it also ensures that whichever country will determine the rate of growth of the world technology in the near future prefers to choose the cutthroat reward structure (and again for $n_{j}(0)>1-\delta$, there exists $T$ such that this country determines the world growth rate for $t>T$ ). Part 2 then immediately follows from Proposition 5.

An interesting implication of this result is that country $j$, which has a stronger labor movement or social democratic party, benefits in welfare terms by having both equality and rapid growth, but in some sense exports its potential labor conflict to country $j^{\prime}$, which now has to choose a reward structure with significantly greater inequality.

In the context of the comparison of the US to Scandinavian economies, the latter clearly have a history of stronger labor movement and social democratic party, suggesting that this might have been one of the factors influencing the specific pattern of asymmetric world equilibrium that has developed over the last several decades. Friedman (2010) provides an overview of existing cross-national historical data on union density which shows that in 1928, just prior to the date when the Swedish Social Democrats took power (1932), its unionization rate was $32.0 \%$. In Denmark, this was $39.7 \%$ and in Norway $17.4 \%$. In the US this number was $9.9 \%$ in 
1928. It is not just the extent of unionization but how it is organized. US Unions like those of Britain tended to be along craft lines with multiple unions in a single firm, making it much more difficult for the labor movement to act collectively. In Scandinavia unions were organized by industry and were much more encompassing. Finally, the rise of social democratic parties which cemented the Scandinavian model into place had its roots in the late 19th century (see Lundberg and Åmark, 2001, for Sweden, Baldwin, 1992, more generally) and its particular universalistic and tax financed nature was a result of what Gourevitch (1986) calls the "Red-Green Coalition" which linked poor rural peasants with urban industrial workers (see also Baldwin, 1992). In the US similar debates took place and the coalitions that formed within the Populist and Progressive movements had Red-Green elements. Though they also managed to push progressive reforms, such as the introduction of the income tax in 1913, these movements were weaker and failed to unite with a factious labor movement. While the 1920s saw left-wing political parties come to power in Denmark (the Social Democrats came to power in 1924) and Norway (Norwegian Labor Party formed its first government in 1928), left-wing US political parties severely declined. Thus just at the critical juncture where many of the institutions of 20th century developed countries states were formed, the strength of labor movements and left-wing political parties was much greater in Scandinavia than in the US.

\section{Conclusion}

In this paper, we have taken a first step towards a systematic investigation of institutional choices in an interdependent world - where countries trade or create knowledge spillovers on each other. Focusing on a model in which all countries benefit and potentially contribute to advances in the world technology frontier, we have suggested that the world equilibrium may necessarily be asymmetric. In our model economy, because effort by entrepreneurs is private information, a greater gap of incomes between successful and unsuccessful entrepreneurs - thus greater inequality - increases innovative effort and a country's contributions to the world technology frontier. Under plausible assumptions, in particular with sufficient risk aversion and a sufficient return to entrepreneurial effort, some countries will opt for a type of "cutthroat" capitalism that generates greater inequality and more innovation and will become the technology leaders, while others will free-ride on the cutthroat incentives of the leaders and choose a more "cuddly" form of capitalism. We have also shown that, paradoxically, starting with similar initial conditions, those that choose cuddly capitalism, though poorer, will be better off than those opting for cutthroat capitalism. Nevertheless, this configuration is an equilibrium because cutthroat capitalists cannot switch to cuddly capitalism without having a large impact on world growth, which would ultimately reduce their own welfare. This perspective therefore suggests that the diversity of institutions we observe among relatively advanced countries, ranging from greater inequality and risk taking in the United States to the more egalitarian societies supported by a strong safety net in Scandinavia, rather than reflecting differences in fundamentals between the citizens of these societies, may emerge as a mutually self-reinforcing equilibrium. If 
so, in this equilibrium, we cannot all be like the Scandinavians, because Scandinavian capitalism depends in part on the knowledge spillovers created by the more cutthroat American capitalism.

Clearly, the ideas developed in this paper are speculative. We have theoretically shown that a specific type of asymmetric equilibrium emerges in the context of a canonical model of growth - with knowledge spillovers combined with moral hazard on the part of entrepreneurs. Whether these ideas contribute to the actual divergent institutional choices among relatively advanced nations is largely an empirical question. We hope that our paper will be an impetus for a detailed empirical study of these issues.

In addition, there are other interesting theoretical questions raised by our investigation. Similar institutional feedbacks may also emerge when countries interact via international trade rather than knowledge spillovers. For example, if different stages of production require different types of incentives, specialization in production resulting in a Ricardian equilibrium may also lead to "institutional specialization". In addition, while we have focused on a specific and simple aspect of institutions, the reward structure for entrepreneurs, our results already hint that there may be clusters of institutional characteristics that co-vary - for example, strong social democratic parties and labor movements leading to cuddly capitalism domestically and to cutthroat capitalism abroad. Institutional choices concerning educational systems, labor mobility, and training investments may also interact with those related to reward structures for entrepreneurs and workers. We believe that these are interesting topics for future study.

\section{References}

Acemoglu, Daron (2009) Introduction to Modern Economic Growth, Princeton University Press.

Acemoglu, Daron, Philippe Aghion and Fabrizio Zilibotti (2006) "Distance to Frontier, Selection, and Economic Growth," Journal of the European Economic Association, MIT Press, vol. 4(1), pages 37-74, 03.

Acemoglu, Daron and Jorn-Steffen Pischke (1998) "Why Do Firms Train? Theory and Evidence" Quarterly Journal of Economics, 113:1, 78-118.

Acemoglu, Daron and Jaume Ventura (2001) "The World Income Distribution" Quarterly Journal of Economics, 117:2, 659-694.

Akkermans, Dirk, Carolina Castaldi, and Bart Los (2009) "Do "liberal market economies' really innovate more radically than 'coordinated market economies'? Hall and Soskice reconsidered," Research Policy, 38, 181-91.

Alesina, Alberto and Edward L. Glaeser (2004) Fighting Poverty in the US and Europe: A World of Difference, New York: Oxford University Press.

Alesina, Alberto, Edward L. Glaeser and Bruce Sacerdote (2001) "Why Doesn't the United States Have a European-Style Welfare State?" Brookings Paper on Economics Activity, Fall 2001, 187-278. 
Alesina, Alberto, Edward L. Glaeser and Bruce Sacerdote (2005) "Work and Leisure in the U.S. and Europe: Why So Different?" NBER Macroeconomic Annual, 1-64.

Alesina, Alberto and with Eliana La Ferrara (2005) "Preferences for Redistribution in the Land of Opportunities," Journal of Public Economics, 89, 897-931.

Algan, Yann, Pierre Cahuc and Marc Sangnier (2011) "Efficient and Inefficient Welfare States," https://sites.google.com/site/pierrecahuc/ unpublished_papers.

Atkinson, Anthony B., Thomas Piketty and Emmanuel Saez (2007) "Top Incomes in the Long Run of History" Journal of Economic Literature, 49:1, 3-71.

Baldwin, Peter (1992) The Politics of Social Solidarity: Class Bases of the European Welfare State, 1875-1975, New York: Cambridge University Press.

Bénabou, Roland J.M. (2000) "Unequal Societies: Income Distribution and the Social Contract," American Economic Review, 90, 96-129.

Bénabou, Roland J.M. and Efe Ok (2001) "Social Mobility and the Demand for Redistribution: The POUM Hypothesis," Quarterly Journal of Economics, 116:2, 447-487.

Bénabou, Roland J.M. and Jean Tirole (2006) "Belief in a Just World and Redistributive Politics," Quarterly Journal of Economics, 121:2, 699-746.

Blanchard, Olivier (2004) "The Economic Future of Europe," Journal of Economic Perspectives, 18:4, 3-26.

Bottazzi, Laura and Giovanni Peri (2003) "Innovation and spillovers in regions: Evidence from European patent data," European Economic Review, 47:4, 687-710.

Cameron, David R. (1978) "The Expansion of the Public Economy: A Comparative Analysis," American Political Science Review, 72, 1243-61.

Cardoso, Fernando H. and Enzi Faletto Enzo (1979) Dependency and Development in Latin America, Berkeley: University of California Press.

Coe, David and Elhanan Helpman (1995) "International R\&D spillovers," European Economic Review vol. 39(5), pages 859-887, May.

Crouch, Colin (2009) "Typologies of Capitalism," in Bob Hancké ed. Debating Varieties of Capitalism: A Reader, New York: Oxford University Press.

Davis, Donald R. (1998) "Does European Unemployment Prop Up American Wages? National Labor Markets and Global Trade," American Economic Review, 88(3), 478-494.

Epstein, Larry G. and Stanley E. Zin (1989) "Substitution, Risk Aversion and Temporal Behavior of Consumption and Asset Returns: A Theoretical Framework" Econometrica, $57: 4, \quad 937-969$.

Esping-Anderson, Gösta (1990) The Three Worlds of Welfare Capitalism, Princeton: Princeton University Press.

Friedman, Gerald (2010) "Labor Unions in the United States," http://eh.net/encyclopedia/article/friedman.unions.us

Gerschenkron, Alexander (1962) Economic backwardness in historical perspective, a book of essays, Belknap Press of Harvard University Press, Cambridge, Massachusetts. 
Griffith, Rachel, Stephen Redding and John Van Reenen (2003) "R\&D and Absorptive Capacity: Theory and Empirical Evidence," Scandinavian Journal of Economics, Wiley Blackwell, vol. 105(1), pages 99-118, 03.

Gourevitch, Peter (1986) Politics in Hard Times, Ithaca: Cornell University Press.

Hall, Bronwyn, Adam Jaffe, and Manuel Trajtenberg (2001) "The NBER Patent Citation Data File: Lessons, Insights and Methodological Tools," NBER Working Paper 8498.

Hall, Peter and David Soskice (2001) Varieties of Capitalism: The Institutional Foundations of Comparative Advantage, Oxford University Press, USA.

Hölmstrom, Bengt (1979) "Moral Hazard and Observability," The Bell Journal of Economics, Vol. 10, No. 1, pp. 74-91.

Howitt, Peter (2000) "Endogenous Growth and Cross-Country Income Differences," American Economic Review, 90:4, 829-846.

Keller, Wolfgang (2001) "Knowledge Spillovers at the World's Technology Frontier," CEPR Discussion Papers 2815.

Kerr, William (2008) "Ethnic Scientific Communities and International Technology Diffusion," Review of Economics and Statistics, 90:3, 518-537

Krueger, Dirk and Krishna Kumar (2004) "US-Europe differences in technology-driven growth: quantifying the role of education," Journal of Monetary Economics, 51:1, 161-190.

Krugman, Paul and Anthony Venables (1996) "Integration, specialization, and adjustment," European Economic Review, 40, 959-967.

Landier, Agustin (2005) "Entrepreneurship and the Stigma of Failure," mimeo.

Lundberg, Urban and Klas Åmark (2001) "Social Rights and Social Security: The Swedish Welfare State, 1900-2000," Scandinavian Journal of History, 26:3, 157-176.

Matsuyama, Kiminori (2002) "Explaining Diversity: Symmetry-Breaking in Complementarity Games," American Economic Review, 92, 241-246.

Matsuyama, Kiminori (2005) "Symmetry-Breaking," in L. Blume and S. Durlauf, eds., the New Palgrave Dictionary of Economics, 2nd Edition, Palgrave Macmillan.

Matsuyama, Kiminori (2007) "Aggregate Implications of Credit Market Imperfections," in D. Acemoglu, K. Rogoff, and M. Woodford, eds., NBER Macroeconomics Annual 2007.

Milesi-Ferretti, Gian Maria, Roberto Perotti and Massimo Rostagno (2002) "Electoral Systems and Public Spending," Quarterly Journal of Economics,

Moene, Karl Ove and Michael Wallerstein (1997) "Pay Inequality," Journal of Labor Economics, 15(3), 403-430.

Nelson, Richard and Edmond Phelps (1966) "Investment in Humans, Technological Diffusion, and Economic Growth," The American Economic Review, 56:1/2 69-75.

OECD (2010) Hours Worked: Average annual hours actually worked, OECD Employment and Labour Market Statistics (database).

OECD (2011) OECD Statistics.

Persson, Torsten and Guido Tabellini (2003) The Economic Effect of Constitutions, 
Cambridge: MIT Press.

Piketty, Thomas (1995) "Social mobility and redistributive politics," Quarterly journal of economics, 110(3), 551-584.

Rodrik, Dani (2008) "Second-Best Institutions," American Economic Review, 98(2), 100104.

Romer, Paul (1990) "Endogenous Technological Change," Journal of Political Economy, 98:5, pp. S71-S102.

Saint-Paul, Gilles and Thierry Verdier (1993) "Education, democracy and growth," Journal of Development Economics, 42, 399-407.

Schor, Juliet (1993) The Overworked American: The Unexpected Decline of Leisure, Basic Books.

Smeeding, Timothy (2002) "Globalization, Inequality, and the Rich Countries of the G20: Evidence from the Luxembourg Income Study (LIS)," Center for Policy Research Working Papers 48, Maxwell School, Syracuse University.

Taylor, Mark Z. (2004) "Empirical Evidence Against Varieties of Capitalism's Theory of Technological Innovation," International Organization, 58, 601-631.

Wallerstein, Immanuel (1974-2011) The Modern World System, 4 Volumes, New York: Academic Press.

WIPO, Economics and Statistics Division (2011) World Intellectual Property Indicators, World Intellectual Property Organization. 


\section{Appendix}

Derivation of Equation (12) . To derive (12), we need to characterize the equilibrium prices and quantities in country $j$ as a function of current technology $N_{j}(t)$. This follows directly from Chapter 18 of Acemoglu (2009). Here it suffices to note that the final good production function (1) implies iso-elastic demand for machines with elasticity $1 / \beta$, and thus each monopolist will charge a constant monopoly price of $\psi /(1-\beta)$, where recall that $\psi$ is the marginal cost in terms of the final good of producing any of the machines given its blueprint (invented or adapted from the world technology frontier). Our normalization that $\psi \equiv 1-\beta$ then implies that monopoly prices and equilibrium quantities are given by $p_{j}^{x}(\nu, t)=1$ and $x_{j}(\nu, t)=L_{j}=1$ for all $j, \nu$ and $t$. This gives that total expenditure on machines in country $j$ at time $t$ will be $X_{j}(t)=(1-\beta) N_{j}(t)$, while total gross output is

$$
Y_{j}(t)=\frac{1}{1-\beta} N_{j}(t) .
$$

Therefore, total net output, left over for distributing across all workers/entrepreneurs is $N Y_{j}(t) \equiv Y_{j}(t)-X_{j}(t)=B N_{j}(t)$, where

$$
B \equiv \frac{\beta(2-\beta)}{1-\beta},
$$

which gives us (12).

\section{Proof of Corollary 2.}

Part 1: It is straightforward to verify that $\left(\frac{\omega_{c}}{\omega_{o}}\right)^{\frac{1}{1-\theta}}$ is decreasing in $A$ (defined in (9)) and $\gamma$. Its dependence on $\theta$ is more complicated. As noted in the text, it is decreasing in $A$. Differentiation and algebra then establishes $A$ is increasing in $\theta$ when $\gamma \leq \bar{\gamma} \equiv 1-\sqrt{\frac{q_{0}\left(1-q_{0}\right)}{q_{1}\left(1-q_{1}\right)}}$. Also, $\left(\frac{\omega_{c}}{\omega_{o}}\right)^{\frac{1}{1-\theta}}$ is decreasing in $\theta$ for fixed $A$. Therefore, $\left(\frac{\omega_{c}}{\omega_{o}}\right)^{\frac{1}{1-\theta}}$ is decreasing in $\theta$ when $\gamma \leq \bar{\gamma}$. Moreover, defining $\theta_{\max } \equiv 1-\frac{\log \left(\frac{1-q_{0}}{1-q_{1}}\right)}{\log (1-\gamma)}>1$, we also have $\lim _{\theta \rightarrow \theta_{\max }}\left(\frac{\omega_{c}}{\omega_{o}}\right)^{\frac{1}{1-\theta}}=0$. Thus there exists $\theta^{*}(\phi, \gamma) \in\left(0, \theta_{\max }(\gamma)\right)$ such that when $\theta \geq \theta^{*}(\phi, \gamma),\left(\frac{\omega_{c}}{\omega_{o}}\right)^{\frac{1}{1-\theta}}<\left(\frac{g_{o}}{g_{c}}\right)^{\frac{1}{\phi}}$, and moreover $\theta \geq$ $\theta^{*}(\phi, \gamma)$ is decreasing in $\gamma$ and $\phi$ (the latter from the fact that the right-hand side of inequality is increasing in $\phi$.

Part 2: When $\theta<1$, Condition 1 requires that

$$
\frac{\omega_{c}}{\omega_{o}}>\frac{\rho-(1-\theta) g_{c}}{\rho-(1-\theta) g_{o}} .
$$

Since $\frac{\omega_{c}}{\omega_{o}}<1$ and $(1-\theta) g_{c}>(1-\theta) g_{o}$, there exists a unique $\bar{\rho}(\theta, \gamma) \in\left[(1-\theta) g_{c}, \infty\right)$ such that is inequality satisfied if and only if $\rho<\bar{\rho}(\theta, \gamma)$. When $\theta>1, \omega_{c}<\omega_{o}<0$, and Condition 1 requires

$$
\frac{\omega_{c}}{\omega_{o}}<\frac{\rho-(1-\theta) g_{c}}{\rho-(1-\theta) g_{o}} .
$$

In this case, some algebra establishes that the same conclusion follows provided that $\gamma \leq \bar{\gamma} \equiv$ $1-\sqrt{\frac{q_{0}\left(1-q_{0}\right)}{q_{1}\left(1-q_{1}\right)}}$ and $\theta \in[1, \bar{\theta}(\gamma)]$ where $\bar{\theta}(\gamma)>1$. Moreover, in both cases $\bar{\rho}(\theta, \gamma)$ is decreasing in $\theta$ and $\gamma$. 
Proof of Proposition 5. We rewrite (22) with a change of variable for $m_{j} \equiv\left(N_{j} / N_{\ell}\right)^{\phi} \leq 1$ as:

$$
\begin{aligned}
\mathcal{W}_{j}\left(m_{j}(t)\right) & =N_{\ell}(t) \max _{u(.) \in[0,1]} \int_{t}^{\infty} e^{-\left(\rho-(1-\theta) g_{c}\right)(\tau-t)} \omega(u(\tau)) m_{j}(\tau)^{\frac{1-\theta}{\phi}} d \tau \\
\dot{m}_{j}(\tau) & \left.=\phi\left[g(u(\tau))-g_{c} m_{j}(\tau)\right)\right] .
\end{aligned}
$$

The solution to this problem would be the "closed loop" best response of follower $j$ to the evolution of the world technology frontier driven by the technology leader, $\ell$. The Markov perfect equilibrium corresponds to the situation in which all countries use "open loop" strategies. However, given our focus on equilibria in which the same country, $\ell$, remains the leader and adopts a cutthroat reward structure (under Condition 1), the open loop and the closed loop solutions coincide, because under this scenario, country $\ell$ always adopts a cutthroat reward structure, regardless of the strategies of other countries. Hence we can characterize the equilibria by deriving the solution to (31).

We now proceed by defining the current-value Hamiltonian, suppressing the country index $j$ to simplify notation,

$$
H(m(t), u(t), \mu(t))=\omega(u(t)) m(t)^{\frac{1-\theta}{\phi}}+\mu(t) \phi\left[g(u(t))-g_{c} m(t)\right],
$$

where $\mu(t)$ is the current-value co-state variable. We next apply the Maximum Principle to obtain a candidate solution. This implies for the control variable (reward structure) $u(t)$ the following bang-bang form:

$$
u(t)\left\{\begin{array}{ccc}
=1 & & \Psi(t)<0 \\
\in[0,1] & \text { if } & \Psi(t)=0 \\
=0 & & \Psi(t)>0
\end{array}\right.
$$

where $\Psi(t)$ is the switching function:

$$
\Psi(t) \equiv\left(\omega_{o}-\omega_{c}\right) m(t)^{\frac{1-\theta}{\phi}}-\mu(t) \phi\left[g_{c}-g_{o}\right] .
$$

In addition,

$$
\begin{aligned}
\dot{m}(t) & =\phi\left[g(u(t))-g_{c} m(t)\right] \text { with } m(0)>0 \text { given } \\
\dot{\mu}(t) & =\left(\rho-(1-\theta) g_{c}+\phi g_{c}\right) \mu(t)-\frac{1-\theta}{\phi} m(t)^{\frac{1-\theta}{\phi}-1} \omega(u(t)),
\end{aligned}
$$

and the transversality condition,

$$
\lim _{t \rightarrow \infty} e^{-\left(\rho-(1-\theta) g_{c}\right) t} \mu(t)=0 .
$$

Now combining (33) with (34), we have

$$
\dot{\Psi}(t)=\left(\rho-(1-\theta) g_{c}+\phi g_{c}\right) \Psi(t)+\left(\omega_{o}-\omega_{c}\right)\left(\rho+\phi g_{c}\right) m(t)^{\frac{1-\theta}{\phi}-1}(\widetilde{m}-m(t)),
$$

where $\widetilde{m}$ is given by (23) in the statement of Proposition 5. Integrating (36), we obtain

$$
\Psi(t)=\left(\omega_{o}-\omega_{c}\right)\left(\rho+\phi g_{c}\right) \int_{t}^{\infty} e^{-\left(\left(\rho-(1-\theta) g_{c}+\phi g_{c}\right)\right)(\tau-t)} m(\tau)^{\frac{1-\theta}{\phi}-1}(m(\tau)-\widetilde{m}) d \tau .
$$


Moreover, (32) implies that in the candidate solution, cutthroat (cuddly) reward structures will be adopted at time $t$ when $\Psi(t)<0(>0)$. Notice first that (34) implies that

$$
\dot{m}(t) \geq \phi\left[g_{o}-g_{c} m(t)\right]
$$

Thus,

$$
m(t) \geq \frac{g_{o}}{g_{c}}+\left(m(0)-\frac{g_{o}}{g_{c}}\right) e^{-\phi g_{c} t}
$$

Next observe the following about the candidate solution.

1. Suppose $\widetilde{m}<g_{o} / g_{c}$ (corresponding to part 1 of Proposition 5). One can first notice that the control variable $u(t)$ can only take the extreme values 0 or 1 . To see this, suppose to obtain a contradiction that in some interval $t \in\left[t_{1}, t_{2}\right], u(t) \in(0,1)$. Then also $\Psi(t)=0$ on that same interval $\left[t_{1}, t_{2}\right]$. Therefore for $t \in\left[t_{1}, t_{2}\right], \dot{\Psi}(t)=0$, but then (36) implies that $m(t)$ is a constant equal to $\widetilde{m}$. Thus $\dot{m}(t)=0$ and $u(t)=\widetilde{u}=\left(g_{c} \widetilde{m}-g_{o}\right) /\left(g_{c}-g_{o}\right)$, which together with $\widetilde{m}<g_{o} / g_{c}$ implies that $\widetilde{u}<0$, yielding a contradiction.

Next consider the following cases:

- If $m(0)>g_{o} / g_{c}$, Then (38) implies that $m(t) \geq g_{o} / g_{c}>\widetilde{m}$ for all $t$. Hence (37) implies that $\Psi(t)>0$ for all $t$, and thus $u(t)=0$ for all $t$ (which also implies from (34) that $m(t)$ is monotonically decreasing towards $g_{o} / g_{c}$ ).

- If $m(0)<g_{o} / g_{c}$, then (38) implies that $\liminf m(t) \geq g_{o} / g_{c}>\widetilde{m}$, and thus $\liminf \Psi(t)>$ 0 . Hence there exists $T^{\prime}$ such that for $t>T^{\prime}, \Psi(t)>0$, and thus $u(t)=0$. Two cases need to be considered:

- Case i) For all $t \in\left[0, T^{\prime}\right], \Psi(t)>0$ and therefore for all $t \geq 0, u(t)=0$ (and $m(t)$ is monotonically increasing towards $\left.g_{o} / g_{c}\right)$.

- Case ii) There exists $t^{\prime} \in\left[0, T^{\prime}\right]$ such that $\Psi\left(t^{\prime}\right)=0$. Let $t_{o}<T$ be the maximum of such dates $t^{\prime}$. We have $\Psi\left(t_{o}\right)=0$. By definition of $t_{o}$, for all $t>t_{o} \Psi(t)>0$. Hence we also have $\Psi^{\prime}\left(t_{o}\right)>0$. Equation (36) implies that $m\left(t_{o}\right)<\tilde{m}$. Suppose now that there is another date $t "<t_{o}$ such that $\Psi\left(t^{\prime \prime}\right)=0$ and take the largest of such dates $t_{1}<t_{o}$. By construction, $\Psi^{\prime}\left(t_{1}\right)<0$. Also given that for all $t \geq t_{o} \Psi(t) \geq 0$, and the continuity of $\Psi(t), \Psi(t)<0$ on the interval $t \in\left(t_{1}, t_{o}\right)$ and $\Psi\left(t_{o}\right)=\Psi\left(t_{1}\right)=0$. Hence for $t \in\left(t_{1}, t_{o}\right)$, we also have $u(t)=1$ and $m(t)$ increasing in $t$ (from (34)). It follows that $m\left(t_{1}\right)<m\left(t_{o}\right)<\widetilde{m}$. However, (36), $\Psi^{\prime}\left(t_{1}\right)<0$ and $\Psi\left(t_{1}\right)=0$ jointly imply that $m\left(t_{1}\right)>\widetilde{m}$, yielding a contradiction Hence there cannot exist another date $t "<t_{o}$ such that $\Psi(t ")=0$. Hence the function $\Psi(t)$ cannot change sign on $\left[0, t_{o}\right)$. Given that at $t_{o} \Psi\left(t_{o}\right)=0$, one should have $\Psi(t)<0$ on $\left[0, t_{o}\right)$.

- From the previous discussion, it follows that there exists at most one date $T \geq 0$ at which the function $\Psi(t)$ changes sign. When such a date $T$ exists, it must be that $\Psi(t)<0$ and $u(t)=1$ for $t \in[0, T)$ and $\Psi(t)>0$ and $u(t)=0$ for $t \in(T, \infty)$. The existence of such time $T$ depends on the sign of $\Psi(0)$. When $\Psi(0)<0$, there exists such switching date 
$T$ at which $\Psi(t)$ changes signs $(<0$ to $>0)$. When conversely $\Psi(0)>0$ the switching function is positive for all $t$. Note also that $m(t)$ is increasing in $m(0)$. Now consider the case where $\theta>1$. Then $\widetilde{m}<0$, and from (37), $\Psi(0)>0$, so that there is no switching. Next consider the case where $\theta<1$. Then $\widetilde{m}>0$, and this together with the condition $\phi>1-\theta$ gives

$$
\begin{aligned}
\frac{\partial \Psi(0)}{\partial m(0)} & =\quad\left(\omega_{o}-\omega_{c}\right)\left(\rho+\phi g_{c}\right) \\
& \times \quad \int_{0}^{\infty} e^{-\left(\left(\rho-(1-\theta) g_{c}+\phi g_{c}\right)\right) \tau} \frac{\partial m(\tau)}{\partial m(0)}\left[\frac{1-\theta}{\phi} m(\tau)-\left(\frac{1-\theta}{\phi}-1\right) \widetilde{m}\right] m(\tau)^{\frac{1-\theta}{\phi}-2} d \tau>0 .
\end{aligned}
$$

Hence $\Psi(0)$ is increasing in $m(0)$, and thus there exists $\bar{m}$ such that $\Psi(0) \gtrless 0$ if $m(0) \gtrless \bar{m}$ (i.e., $\left.n(0) \gtrless \bar{m}^{1 / \phi}\right)$.

2. Suppose $1>\widetilde{m}>g_{o} / g_{c}$ (corresponding to part 2 of Proposition 5). Then the following choice of rewards structure satisfies (32):

$$
u(t)=\left\{\begin{array}{ccc}
0 & \text { if } & m(t)>\widetilde{m} \\
u^{*} & \text { if } & m(t)=\widetilde{m} \\
1 & \text { if } & m(t)<\widetilde{m}
\end{array}\right.
$$

where $u^{*}$ is such that $\widetilde{m}=g\left(u^{*}\right) / g_{c}$, and when $m(t)=\widetilde{m}$, we have $\dot{m}(t)=0$ and $\Psi(t)=0$, ensuring that this choice of reward structure does indeed satisfy (32). Note also that in this case whenever $m(t)>\widetilde{m}(m(t)<\widetilde{m}) m(t)$ declines (increases) to $\widetilde{m}$ monotonically, and at $m(t)=\widetilde{m}$, it remains constant.

3. Suppose $\widetilde{m}>1$ (corresponding to part 3 of Proposition 5). In this case, $\Psi(t)<0$ for all $t$ (regardless of initial conditions), and thus $u(t)=1$ for all $t$. Given this reward structure, in this case $m(t)$ monotonically converges to 1 .

Finally, in each case, the candidate solution satisfies the transversality condition (35), and the assumption that $1-\theta<\phi$ ensures that Mangasarian's sufficiency condition is satisfied (e.g., Acemoglu, 2009, Chapter 7). Thus the candidate solution characterized above is indeed a solution and is unique. This completes the proof of Proposition 5.

Proof of Proposition 7. We will prove that under the hypotheses of the proposition, there does not exist a symmetric equilibrium. We focus on the case in which preferences are given by (7). The proof for the case in which they are given by (8) is similar.

Suppose first that all countries choose a cuddly reward structure for all $t \geq 0$. Then the world economy converges to a Balanced Growth Path (BGP) where every country has the same level of income, $N_{j}(t) /(1-\beta)=N(t) /(1-\beta)$, and grows at the same rate, which from (6) is equal to $N(t) / N(t)=g_{o}$. The time $t$ welfare of country $j$ in this equilibrium can be written as

$$
\mathcal{W}_{j}^{o}(t)=\int_{t}^{\infty} e^{-\delta(\tau-t)} \omega_{o}\left(\frac{N_{j}(\tau)}{N(\tau)}\right)^{1-\theta} N(\tau)^{1-\theta} d \tau,
$$


which implies that for any $\epsilon>0$, there exists $T_{1}$ such that for all $t>T_{1}$, we are close enough to the steady state equilibrium in the sense that $1-\epsilon<\frac{N_{j}(t)}{N(t)}<1+\epsilon, \dot{N} / N<g_{o}+\epsilon$, and

$$
\mathcal{W}_{j}^{o}(t)<\frac{\omega_{o} N(t)^{1-\theta}(1+\epsilon)^{1-\theta}}{\rho-(1-\theta)\left(g_{o}+\epsilon\right)}
$$

Consider now a deviation of one country $k$ to a cutthroat reward structure at all times $t>T_{1}$. Denote by $\widehat{N}_{j}(t)$, the new growth path of country $j$ and by $\widehat{N}(t)$ the growth path to the world technology frontier. The world economy converges again to a new BGP with growth rate $\widehat{g}$. This BGP growth rate can be written as

$$
\widehat{g}=\frac{1}{J^{\frac{\phi}{1+\phi}}}\left[(J-1) g_{o}^{\frac{1}{\phi} \frac{\sigma-1}{\sigma}}+g_{c}^{\frac{1}{\phi} \frac{\sigma-1}{\sigma}}\right]^{\frac{\sigma}{\sigma-1} \frac{\phi}{1+\phi}}>g_{o} .
$$

After this deviation, we have $\widehat{N}_{k}(t)>N_{k}(t)$ and $\widehat{N}_{k}(t)>N(t)$ for all $t>T_{1}$. Then for $\epsilon_{1}>0$, there exists $T_{1}^{\prime}>T_{1}$ and $\epsilon_{1}^{\prime}$ such that for all $t>T_{1}^{\prime}, \widehat{\widehat{N}}_{k} / \widehat{N}_{k} \geq \widehat{g}-\epsilon_{1}$, and welfare of country $k$ satisfies

$$
\begin{aligned}
\mathcal{W}_{k}^{c}\left(T_{1}\right) & =\int_{T_{1}}^{\infty} e^{-\rho\left(t-T_{1}\right)} \omega_{c} \widehat{N}_{k}(t)^{1-\theta} d t \\
& =\int_{T_{1}}^{T_{1}^{\prime}} e^{-\rho\left(t-T_{1}\right)} \omega_{c} \widehat{N}_{k}(t)^{1-\theta} d t+e^{-\rho\left(T_{1}^{\prime}-T_{1}\right)} \int_{T_{1}^{\prime}}^{\infty} e^{-\rho\left(t-T_{1}^{\prime}\right)} \omega_{c} \widehat{N}_{k}(t)^{1-\theta} d t \\
& >e^{-\rho\left(T_{1}^{\prime}-T_{1}\right)} \omega_{c} \frac{\widehat{N}_{k}\left(T_{1}^{\prime}\right)^{1-\theta}}{\rho-(1-\theta)\left(\widehat{g}-\epsilon^{\prime}\right)} .
\end{aligned}
$$

Now using the fact that $\widehat{N}_{k}\left(T_{1}^{\prime}\right) \geq N_{k}\left(T_{1}^{\prime}\right) \geq e^{g_{o}\left(T_{1}^{\prime}-T_{1}\right)} N_{k}\left(T_{1}\right)$, a sufficient condition for the deviation for country $k$ to be profitable is

$$
\begin{aligned}
e^{-\left(\rho-(1-\theta) g_{o}\right)\left(T_{1}^{\prime}-T_{1}\right)} \omega_{c} \frac{N_{k}\left(T_{1}\right)^{1-\theta}}{\rho-(1-\theta)\left(\widehat{g}-\epsilon_{1}\right)} & >\omega_{o} \frac{N_{k}\left(T_{1}\right)^{1-\theta}(1+\epsilon)^{1-\theta}}{\rho-(1-\theta)\left(g_{o}+\epsilon\right)} \\
& >\mathcal{W}_{k}^{o}\left(T_{1}\right)=\int_{T_{1}}^{\infty} e^{-\left(\rho-(1-\theta) g_{o}\right)\left(t-T_{1}\right)} \omega_{o} N_{k}(t)^{1-\theta} d t .
\end{aligned}
$$

Rearranging terms, this can be written as

$$
\left(\frac{\omega_{c}}{\omega_{o}}\right)^{\frac{1}{1-\theta}}>(1+\epsilon) e^{\frac{\rho-(1-\theta) g_{o}}{1-\theta}\left(T_{1}^{\prime}-T_{1}\right)}\left(\frac{\rho-(1-\theta)\left(\widehat{g}-\epsilon_{1}\right)}{\rho-(1-\theta)\left(g_{0}+\epsilon\right)}\right)^{\frac{1}{1-\theta}} .
$$

Next suppose that all countries adopt a cutthroat reward structure for all $t \geq 0$. In this case, the world economy converges to a BGP where every country has the same level of income and grows at the same rate, which from (6) is equal to $N(t) / N_{j}(t)=g_{c}$. With a similar reasoning, for $\epsilon>0$, there exists $T_{2}$ such that for all $j$ and $t>T_{2}, 1-\epsilon<N_{j}(t) / N(t)<1+\epsilon$ and $N / N<g_{c}+\epsilon$. Thus

$$
\mathcal{W}_{j}^{c}(t)<\frac{\omega_{c} N(t)^{1-\theta}(1+\epsilon)^{1-\theta}}{\rho-(1-\theta)\left(g_{c}+\epsilon\right)}
$$


Consider now a deviation of one country $k$ to a cuddly reward structure at all time $t>T_{2}$ while all other countries $j \neq k$ stay with cutthroat reward structures throughout. Denote the path of technology of country $j$ after this deviation by $\widetilde{N}_{j}(t)$, and the path of world technology frontier by $\widetilde{N}(t)$. Clearly, $\widetilde{N}(t) / \widetilde{N}_{j}(t)=\widetilde{g}<g_{c}$, and moreover $\widetilde{N}_{k}(t) \leq N_{k}(t)$ for all $t>T_{2}$. Let us also note that

$$
\widetilde{g}=\frac{\dot{\tilde{N}}_{j}(t)}{\widetilde{N}(t)}=\frac{1}{J}\left[(J-1) g_{c}^{\frac{\sigma-1}{\sigma}}+g_{o}^{\frac{\sigma-1}{\sigma}}\right]^{\frac{\sigma}{\sigma-1}}>g_{o}
$$

Now, again fixing $\epsilon_{2}>0$, there exists $T_{2}^{\prime}>T_{2}$ such that for all $t>T_{2}^{\prime}, \tilde{N}_{k} / \widetilde{N}_{k} \geq \widetilde{g}-\epsilon_{2}$, and the welfare of country $k$ satisfies

$$
\begin{aligned}
\mathcal{W}_{k}^{o}\left(T_{2}\right) & =\int_{T_{2}}^{\infty} e^{-\rho(t-T)} \omega_{o} \widetilde{N}_{k}(t)^{1-\theta} d t \\
& =\int_{T_{2}}^{T_{2}^{\prime}} e^{-\rho\left(t-T_{2}\right)} \omega_{o} \widetilde{N}_{k}(t)^{1-\theta} d t+e^{-\rho\left(T_{2}^{\prime}-T_{2}\right)} \int_{T_{2}^{\prime}}^{\infty} e^{-\rho\left(t-T^{\prime \prime}{ }_{2}\right)} \omega_{o} \widetilde{N}_{k}(t)^{1-\theta} d t \\
& >\omega_{o} N_{k}\left(T_{2}\right)^{1-\theta} \int_{T_{2}}^{T_{2}^{\prime}} e^{-\rho(t-T)} e^{(1-\theta) g_{o}(t-T)} d t+e^{-\rho\left(T_{2}^{\prime}-T_{2}\right)} \omega_{o} \frac{N_{k}\left(T_{2}\right)^{1-\theta} e^{(1-\theta) g_{0}\left(T_{2}^{\prime}-T_{2}\right)}}{\rho-(1-\theta)\left(\widetilde{g}-\epsilon_{2}\right)} \\
& >\omega_{o} N_{k}\left(T_{2}\right)^{1-\theta} \frac{1-e^{-\left(\rho-(1-\theta) g_{o}\right)\left(T_{2}^{\prime}-T_{2}\right)}}{\rho-(1-\theta) g_{o}}+e^{-\left(\rho-(1-\theta) g_{o}\right)\left(T_{2}^{\prime}-T_{2}\right)} \omega_{o} \frac{N_{k}\left(T_{2}\right)^{1-\theta}}{\rho-(1-\theta)\left(\widetilde{g}-\epsilon_{2}\right)},
\end{aligned}
$$

where the second line uses the fact $\widetilde{N}_{k}(t)>N_{k}\left(T_{2}\right) e^{g_{0}\left(t-T_{2}\right)}$. Then a sufficient condition for the deviation to the cuddly reward structure for country $k$ to be profitable is

$$
e^{-\left(\rho-(1-\theta) g_{o}\right)\left(T_{2}^{\prime}-T_{2}\right)} \omega_{o} \frac{N_{k}\left(T_{2}\right)^{1-\theta}}{\rho-(1-\theta)\left(\widetilde{g}-\epsilon_{2}\right)}>\omega_{c} \frac{N\left(T_{2}\right)^{1-\theta}(1+\epsilon)^{1-\theta}}{\rho-(1-\theta)\left(g_{c}+\epsilon\right)} .
$$

Since $N_{k}\left(T_{2}\right)>N\left(T_{2}\right)(1-\epsilon)$, this sufficient condition can be rewritten as

$$
\frac{1-\epsilon}{1+\epsilon}\left(\frac{\left.\rho-(1-\theta)\left(g_{c}+\epsilon\right)\right)}{\rho-(1-\theta)\left(\widetilde{g}-\epsilon_{2}\right)}\right)^{\frac{1}{1-\theta}} e^{-\frac{\rho-(1-\theta) g_{o}}{1-\theta}\left(T_{2}^{\prime}-T_{2}\right)}>\left(\frac{\omega_{c}}{\omega_{o}}\right)^{\frac{1}{1-\theta}} .
$$

Thus combining (39) and (40), we obtain that the following is a sufficient condition for an asymmetric equilibrium not to exist after some time $T=\max \left\{T_{1}, T_{2}\right\}$ :

$\frac{1-\epsilon}{1+\epsilon}\left(\frac{\left.\rho-(1-\theta)\left(g_{c}+\epsilon\right)\right)}{\rho-(1-\theta)\left(\widetilde{g}-\epsilon_{2}\right)}\right)^{\frac{1}{1-\theta}} e^{-\frac{\rho-(1-\theta) g_{o}}{1-\theta}\left(T_{2}^{\prime}-T_{2}\right)}>\left(\frac{\omega_{c}}{\omega_{o}}\right)^{\frac{1}{1-\theta}}>\frac{1-\epsilon}{1+\epsilon} e^{\frac{\rho}{1-\theta}\left(T_{1}^{\prime}-T_{1}\right)}\left(\frac{\rho-(1-\theta)\left(\widehat{g}-\epsilon_{1}\right)}{\rho-(1-\theta)\left(g_{o}+\epsilon\right)}\right)^{\frac{1}{1-\theta}}$.

Now note that as $\sigma \uparrow 0$ in (6), $\widehat{g} \longrightarrow g_{c}$ and $\widetilde{g} \longrightarrow g_{c}$. Therefore, for $\epsilon^{\prime}>0$, there exists $\bar{\sigma}<0$ such that for $\sigma>\bar{\sigma}, \widehat{g}-\epsilon^{\prime}<g_{o}$ and $\widetilde{g}-\epsilon^{\prime}<g_{o}$. Thus choosing $\epsilon, \epsilon_{1}, \epsilon_{2}$, and $\epsilon^{\prime}$ sufficiently small, the following is also a sufficient condition:

$$
e^{-\frac{\rho-(1-\theta) g_{o}}{1-\theta}\left(T_{2}^{\prime}-T_{2}\right)}>\left(\frac{\omega_{c}}{\omega_{o}}\right)^{\frac{1}{1-\theta}}>e^{\frac{\rho-(1-\theta) g_{o}\left(T_{1}^{\prime}-T_{1}\right)}{1-\theta}}\left(\frac{\rho-(1-\theta) g_{c}}{\rho-(1-\theta) g_{o}}\right)^{\frac{1}{1-\theta}} .
$$

Finally, choosing $\rho$ sufficiently close to $(1-\theta) g_{c}$ and defining $\bar{T} \equiv\left\{T_{1}^{\prime}-T_{1}, T_{2}^{\prime}-T_{2}\right\}$, a further sufficient condition is obtained as

$$
e^{-\left(g_{c-} g_{o}\right) \bar{T}}>\left(\frac{\omega_{c}}{\omega_{o}}\right)^{\frac{1}{1-\theta}}>e^{\left(g_{c}-g_{o}\right) \bar{T}}\left(\frac{\rho-(1-\theta) g_{c}}{\rho-(1-\theta) g_{o}}\right)^{\frac{1}{1-\theta}} .
$$


For given choices of $\epsilon$ and $\epsilon_{1}, \bar{T}$ is fixed. Hence there exists $\bar{\rho}>(1-\theta) g_{c}$ such that for $(1-\theta) g_{c}<\rho<\bar{\rho}$, the right-hand side term inequality is close to zero and the left-hand term is given by some positive number. Next recall that

$$
\left(\frac{\omega_{c}}{\omega_{o}}\right)^{\frac{1}{1-\theta}}=\frac{\left(q_{1} A^{1-\theta}+\left(1-q_{1}\right)^{\frac{1}{1-\theta}}\right)(1-\gamma)}{q_{1} A+\left(1-q_{1}\right)} .
$$

When $\theta<1$, this tends to 0 as $\gamma \rightarrow 1-\left(\frac{q_{0}}{q_{1}}\right)^{1 /(1-\theta)}$. When $\theta>1$, this tends to 0 as $\gamma \rightarrow$ $1-\left(\frac{1-q_{0}}{1-q_{1}}\right)^{1 /(1-\theta)}$. Thus in both cases (for a fixed value of $\theta$ ) their exists $\bar{\gamma}<1$ such that for $\gamma>\bar{\gamma},\left(\frac{\omega_{c}}{\omega_{o}}\right)^{\frac{1}{1-\theta}}$ is sandwiched between these two terms, ensuring that (43) is satisfied and a symmetric equilibrium does not exist.

Finally, when these conditions are satisfied, a similar analysis to that in the proof of Proposition 5 implies that the equilibrium will take the form where after some $T$, subset of countries choose a cuddly reward structure and the remaindered choose a cutthroat reward structure. 